FRBSF Working Paper 2002-05

\title{
The Empirical Relationship between Average Asset Correlation, Firm Probability of Default and Asset Size
}

\author{
Jose A. Lopez \\ Economic Research Department \\ Federal Reserve Bank of San Francisco \\ 101 Market Street \\ San Francisco, CA 94705 \\ Phone: (415) 977-3894 \\ jose.a.lopez@sf.frb.org
}

Print date: June 17, 2002

\begin{abstract}
The asymptotic single risk factor (ASRF) approach is a simplified framework for determining regulatory capital charges for credit risk and has become an integral part of how credit risk capital requirements are to be determined under the second Basel Accord. Within this approach, a key regulatory parameter is the average asset correlation. In this paper, we examine the empirical relationship between the average asset correlation, firm probability of default and firm asset size measured by the book value of assets by imposing the ASRF approach within the KMV methodology for determining credit risk capital requirements. Using data from year-end 2000, credit portfolios consisting of U.S., Japanese and European firms are analyzed. The empirical results suggest that average asset correlation is a decreasing function of probability of default and an increasing function of asset size. When compared with the average asset correlations proposed by the Basel Committee on Banking Supervision in November 2001, the empirical average asset correlations further suggest that accounting for firm asset size, especially for larger firms, may be important. In conclusion, the empirical results suggest that a variety of factors may impact average asset correlations within an ASRF framework, and these factors may need to be accounted for in the final calculation of regulatory capital requirements for credit risk.
\end{abstract}

Acknowledgements: The views expressed here are those of the author and not necessarily those of the Federal Reserve Bank of San Francisco or the Federal Reserve System. This work was initiated after several conversations with David Jones from the Federal Reserve Board of Governors, and I gratefully acknowledge his assistance, suggestions and comments. I thank Steven Kealhofer and Jeff Bohn of KMV, LLC for providing me with access to the Portfolio Manager ${ }^{\mathrm{TM}}$ software used in the analysis. I also thank Yim Lee, Ashish Das, Kimito Iwamoto, Sherry Kwok, Amnon Levy and Jing Zhang, all from KMV, for their assistance with the data and the software. Finally, I thank Akira Ieda, Mark Levonian, Phillip Lowe, George Pennacchi, Marc Saidenberg, and participants at the May 2002 BIS conference on "Basel II: An Economic Assessment” for their comments and suggestions. 


\section{Introduction}

As discussed by Gordy (2001), the asymptotic single risk factor (ASRF) approach is a general framework for determining regulatory capital requirements for credit risk, and it has become an integral part of the second Basel Accord. ${ }^{1}$ A key variable in the ASRF approach is the correlation of a given firm's assets with the common risk factor that summarizes general economic conditions. In economic capital calculations, every obligor would have a unique asset correlation, but for the purposes of regulatory capital calculations, such a multitude of parameters is infeasible. Instead, it has been proposed that an average correlation be used for every obligor.

Specifically, in the Basel Committee on Banking Supervision (BCBS) document of January 2001 (BCBS, 2001a), asset correlations were assumed to take a value of 0.20 for all obligors. That is, the asset values of every obligor were assumed to have a factor loading of 0.20 with the common risk factor. In response to practitioner feedback and its quantitative impact studies, the BCBS proposed an alternative formula in November 2001 that would make asset correlation a decreasing function of firm probability of default; see BCBS (2001c).

In this paper, we investigated empirically whether there are any patterns in the average asset correlation variable that may need to be accounted for in regulatory capital calculations. To do so, we imposed the ASRF approach on the KMV methodology for determining credit risk capital charges. ${ }^{2}$ We then examined the relationship between portfolios' average asset correlations, firms' probabilities of default and firms' asset sizes as measured by the book value of assets. The analysis was conducted on portfolios of U.S., Japanese and European firms, as well as on a "world" portfolio consisting of all of these firms, using data from year-end 2000. Subportfolios based on either firm default probability or asset size were constructed for the

\footnotetext{
${ }^{1}$ See Gordy (2000a, b) for further discussion of the ASRF approach,

2 The software firm KMV, LLC is a leader in the field of credit risk modeling and capital budgeting. This study was conducted using their Portfolio Manager ${ }^{\mathrm{TM}}$ software, which they kindly provided for this study. Note that the analysis was conducted using Portfolio Manager, version 1.4.7 and prior to the release of Portfolio Manager,
} version 2.0. 
univariate analysis, and subportfolios based on both variables were used for the bivariate analysis.

Our empirical results indicate that average asset correlation is a decreasing function of the probability of default, as suggested by BCBS (2001c). This univariate result suggests that the reasons why firms experience rising default probabilities are mainly idiosyncratic and not tied as closely to the general economic environment summarized by the common risk factor. In a direct comparison, the calibrated average asset correlations derived in this paper generally match those derived from the formula presented in the November 2001 BCBS proposal.

Our empirical results further indicate that average asset correlation is an increasing function of firm asset size. That is, as firms increase the book value of their assets, they become more correlated with the general economic environment and the common risk factor. The intuition for this result is that larger firms can generally be viewed as portfolios of smaller firms, and such portfolios would be relatively more sensitive to common risks than to idiosyncratic risks. Although these results suggest that average asset correlation is related to firm size, the policy implications for regulatory capital requirements require further analysis; for example, the issue of how to define firm size is nontrivial. Also, whether such an adjustment is material to the final capital requirements relative to the their many components is an open question.

The bivariate results support both sets of univariate results and appear to highlight an additional and potentially important relationship between the three variables. The results indicate that the decreasing relationship between average asset correlation and default probability is more pronounced for larger firms. In other words, the average asset correlation for larger firms is more sensitive to firm probability of default than it is for smaller firms. In direct comparison with the regulatory average asset correlations derived from the November proposal, the greatest deviations from the calibrated values are for portfolios composed of the largest firms, suggesting the potential value of incorporating firm size into the regulatory formula for average asset correlations. 
These results provide suggestive evidence that both firm probability of default and firm size impact average asset correlation within an ASRF framework. Hence, further work regarding whether regulatory capital requirements should take further account of such firm-specific factors seems warranted. However, the limitations to these empirical results, such as our simple maturity and granularity assumptions, must be considered in light of the various components that constitute the Basel II credit risk capital requirements.

The paper is organized as follows. Section II summarizes the KMV methodology for credit risk modeling, describes how the ASRF framework was imposed onto it, and presents the credit portfolios used in the analysis. Section III presents the presents the calibrated empirical results. Section IV presents the comparison of the calibrated average asset correlations with those derived from the November 2001 regulatory formula, and Section V concludes.

\section{Methodology}

\section{II.A. Summary of the KMV methodology}

The theoretical core of the KMV methodology for evaluating credit risk is the Merton model of a firm's stock as an option on the underlying assets. ${ }^{3}$ To measure the credit risk of a loan to a firm, the KMV methodology models the distribution of the firm's asset value over the chosen planning horizon and the corresponding distribution of the loan's value. This loan value distribution explicitly account for default and changes in firm credit quality.

In general, the KMV methodology, as implemented in their Portfolio Manager ${ }^{\mathrm{TM}}$ (PM) software, models the value of the assets of firm $\mathrm{i}$, denoted as $\mathrm{A}_{\mathrm{it}}$, at a given horizon. At the horizon $\mathrm{H}$ of interest, $\mathrm{A}_{\mathrm{iH}}$ is modeled as

$$
\ln \left(\mathrm{A}_{\mathrm{iH}}\right)=\ln \left(\mathrm{A}_{\mathrm{i} 0}\right)+\left(\mu_{\mathrm{i}}-\frac{\sigma_{\mathrm{i}}^{2}}{2}\right) \mathrm{t}_{\mathrm{H}}+\sigma_{\mathrm{i}} \sqrt{\mathrm{t}_{\mathrm{H}}} \varepsilon_{\mathrm{iH}},
$$

\footnotetext{
${ }^{3}$ For a more complete discussion of the KMV methodology for evaluating credit risk, see Crosbie and Bohn (2001).
} 
where $\mu_{\mathrm{i}}$ is the asset value drift term (typically positive), $\sigma_{\mathrm{i}}^{2}$ is the firm's asset volatility, $\mathrm{t}_{\mathrm{H}}$ is the amount of time from period t to the horizon $\mathrm{H}$, and the firm-specific error term $\varepsilon_{\mathrm{iH}}$ is a weighted average of common (or systematic) random factors and an idiosyncratic random factor. That is, $\varepsilon_{\mathrm{iH}}$ is modeled as

$$
\varepsilon_{\mathrm{iH}}=\mathrm{R}_{\mathrm{i}} \xi_{\mathrm{H}}+\sqrt{1-\mathrm{R}_{\mathrm{i}}^{2}} v_{\mathrm{iH}}
$$

where $\mathrm{R}_{\mathrm{i}}{ }^{2}$ measures the percentage of the firm's asset return variance attributable to a common risk factor, $\xi_{\mathrm{H}}$ is a random variable representing the $\mathrm{H}$-period-ahead composite risk factor, and $v_{\mathrm{iH}}$ is an idiosyncratic random variable. Both $\xi_{\mathrm{iH}}$ and $v_{\mathrm{iH}}$ have a standardized variance of one. This decomposition of $\varepsilon_{\mathrm{iH}}$ ensures that it has a variance of one. Note that the $\mathrm{R}_{\mathrm{i}}{ }^{2}$ is referred to as the asset correlation for firm $i$.

For each firm of interest, KMV determines its overall liabilities at time H. For a particular realization of future asset value $\mathrm{A}_{\mathrm{iH}}$, a "distance to default" measure is calculated and used to determine a firm's “expected default frequency"TM (or $\mathrm{EDF}^{\mathrm{TM}}$ ) based on KMV's proprietary default database. The firm's EDF value and its loans' recovery rates permit the calculation of the loan values if the firm defaults. For non-default states, the loans are valued by discounting their cashflows using market-based credit spreads corresponding to the firm's credit quality. Individual firm calculations can be aggregated up to the portfolio level in order to determine the distribution of loan portfolio returns, which in turn can be used for determining economic capital allocations and other credit risk management calculations.

\section{II.B. Application of the ASRF framework to the KMV methodology}

In order to establish regulatory capital requirements applicable across institutions and across credit risk models, the regulatory proposals currently being considered by the BCBS are based on a very general modeling framework, known as the asymptotic single risk factor (ASRF) approach. As described by Gordy (2001), the ASRF approach assumes that a single risk factor is 
responsible for credit quality movements across all obligors in an infinitely granular portfolio. ${ }^{4}$ Each obligor has a unique asset correlation $\mathrm{R}_{\mathrm{i}}^{2}$ with the common risk factor, and the realization of this factor determines the obligors' individual outcomes. A further simplifying assumption that is often imposed is that the obligors all have a common (or average) asset correlation with the composite risk factor; i.e., $\mathrm{R}_{\mathrm{i}}^{2}=\mathrm{R}^{2} \forall \mathrm{i}$. This assumption is needed for regulatory capital calculations in order to reduce the number of model parameters required. Within this analytic framework, the regulatory capital requirement for a portfolio equals the sum of the regulatory capital requirements for the individual credits. This additive property permits the "bucketing" of credits based on certain characteristics, such as firm default probability and recovery rates. This property of the ASRF approach clearly simplifies the allocation of regulatory capital.

To impose the ASRF approach within the KMV methodology, a number of restrictions were imposed on the PM software. The most important restriction was imposing a single risk factor. Within the KMV methodology, there are about 110 factors based on global, regional, country, sector and industry effects. These various factors are aggregated based on firm characteristics to construct a firm's composite factor. For example, the return on the composite factor $\left(\right.$ denoted $\mathrm{CF}_{\mathrm{i}}$ ) for a U.S. domestic firm that is $60 \%$ involved in paper production and $40 \%$ in lumber production is

$$
\mathrm{CF}_{\mathrm{i}}=1.0 \mathrm{r}_{\mathrm{USA}}+0.6 \mathrm{r}_{\text {paper }}+0.4 \mathrm{r}_{\text {lumber }} \text {, }
$$

where $r_{U S A}, r_{\text {paper }}$ and $r_{\text {lumber }}$ are the returns on the factors for the entire U.S. economy, the global paper industry and the global lumber industry, respectively. A regression of firm i's asset returns on the weighted average factor $\mathrm{CF}_{\mathrm{i}}$ provides the asset correlation $\mathrm{R}_{\mathrm{i}}{ }^{2}$ used in the asset value simulations.

Thus, to impose the ASRF approach, we collapsed the many factors into a single factor

\footnotetext{
4 The impact of the assumption of infinitely granular portfolios was not part of our analysis to date. In our analysis, we imposed the assumption of common loan sizes across the obligors. We further assumed that the numbers of obligors in our sample portfolios were sufficiently large for this assumption to hold. Further research into the validity of these assumptions is necessary.
} 
common to all obligors in the credit portfolio. This restriction is imposed by forcing all of the firms to have the same degree of dependence on the same country and industry factors. In our analysis, we assumed that all obligors were dependent on the U.S. country factor (regardless of their country of origin) and on the unassigned industry factor, known as N57 within the KMV industry database..$^{5}$ The common degree of dependence was imposed by assuming a common $\mathrm{R}^{2}$ value for all obligors. This common $\mathrm{R}^{2}$ value is termed the average asset correlation, even though it is not strictly an average, and it will be denoted here as $\bar{\rho}_{\mathrm{A}}$. These two restrictions are obviously quite strong, but necessary for applying the ASRF framework.

There is no theoretical answer as to what the value of the average asset correlation should be, and thus purely empirical values must be determined. To calibrate the empirical value of $\bar{\rho}_{\mathrm{A}}$ for a portfolio at a specified loss tail quantile, we minimized the absolute difference between the credit losses indicated by the unconstrained PM model and by the ASRF-constrained version. The calibrations were conducted using a grid search over a reasonable range for $\bar{\rho}_{\mathrm{A}}$ values. The convergence criteria used were that the calibrated $\bar{\rho}_{\mathrm{A}}$ values would only have up to four significant digits and that the dollar differences between the two models' capital charges at the specified quantile were less than $0.1 \%$ of the total portfolio size. The calibrated $\bar{\rho}_{\mathrm{A}}$ values correlations for credit portfolios composed of firms with similar default probabilities, asset sizes and national origin are the core contribution of this paper.

The third restriction needed to impose the ASRF framework within the PM software is that the recovery rate is constant. For the sake of simplifying our analysis, we also imposed a recovery rate of $50 \%$ across all obligors. Although this is a strong assumption, we know that capital charges within the PM software for portfolios with other values are a simple multiple of each other.

\footnotetext{
${ }^{5}$ Within the ASRF framework, the recommended capital requirements are independent of the common factor chosen. However, in the empirical implementation, differences will arise when different factor specifications are used. These differences should be minor, and preliminary results support this hypothesis.
} 
The fourth restriction imposed on the PM software for our analysis was a one-year maturity for all credits. This restriction is not explicitly required by the ASRF framework. In fact, the current average maturity assumed in BCBS (2000a) is three years. Further research on the impact of maturity on the calibrated $\bar{\rho}_{\mathrm{A}}$ values derived within the ASRF approach.

\section{II.C. The procedure for generating and analyzing the average asset correlations}

The procedure for implementing the ASRF approach within the PM software and analyzing the calibrated average asset correlations consists of three steps. The first step is to create the portfolios of interest based on firm EDF values, firm asset sizes or both. This step is described in detail in Section II.D. The loans to the chosen firms are then structured to have a maturity of one year, a floating rate coupon and a common commitment size of $\$ 100$ million. These restrictions obviously impact the nature of the credit portfolios being analyzed; for example, the standard commitment size precludes analysis of the granularity issue. Further research into this issue is required. However, the empirical results should provide meaningful insight into the relationships of interest.

The second step consists of running the unconstrained version of the PM software on the constructed portfolios in order to generate the capital required at the one-year horizon for the $99.5 \%$ and $99.9 \%$ percentiles of the loss distribution. ${ }^{6}$ Of the various definitions of capital used in the PM software, we chose to use capital in excess of expected loss. That is, PM generates the portfolio's credit loss distribution, designates its mean as the expected loss, and presents the tail quantiles as credit losses beyond the expected loss. Credit losses at the one-year horizon are transformed into capital charges by discounting them to the present with the appropriate risk-free rate. Total capital is the sum of the discounted expect loss and the specified tail loss.

\footnotetext{
6 The number of simulations that we typically used in our analysis was 100,000 runs, which is the number recommended by KMV for analysis of the $99.9 \%$ tail quantile. Note that BCBS (2001b) states that the confidence interval to be used in setting regulatory capital requirements may be increased from $99.5 \%$ to $99.9 \%$.
} 
The third step is to calibrate the portfolios' $\bar{\rho}_{\mathrm{A}}$ values as previously described. The results for the aggregate portfolios, portfolios based on EDF categories, portfolios based on size categories and portfolios based on both variables are then analyzed.

\section{II.D. Credit portfolios of interest}

For this study, we constructed national credit portfolios of U.S., Japanese and European firms. The European portfolios consisted of firms based in Britain, France, Germany, Italy and the Netherlands. We also examined aggregate (or "world") portfolios that included all of the firms in the national portfolios. Aside from the question of firms' national origins, the construction of these credit portfolios required a balance between two criteria. The first criterion was constructing portfolios that had EDF and asset size ranges that were of economic interest. The second criterion was insuring that the portfolios had a sufficient number of credits to avoid small sample concerns.

With respect to the EDFs, the portfolios were basically constructed using the S\&P rating categories set within KMV's Credit Monitor ${ }^{\circledR}$ database as of year-end 2000; see Table 1. The rating categories were collapsed into five EDF categories and held constant for our analysis. The first EDF category ranged from zero to $0.05 \%$ and corresponded to AAA and AA-rated firms; the second EDF category ranged from $0.05 \%$ to $0.52 \%$ and corresponded to A and BBB-rated firms; the third EDF category ranged from $0.52 \%$ to $2.03 \%$ and corresponded to BB-rated firms; the fourth EDF category ranged from $2.03 \%$ to $6.94 \%$ and corresponded to B-rated firms; and the fifth EDF category ranged from $6.94 \%$ to $20 \%$, the maximum EDF value permitted, and corresponded to the remaining $\mathrm{C}$ and D-rated firms. ${ }^{7}$

With respect to asset size, the economic criterion for constructing portfolios was less

\footnotetext{
7 Note that in constructing portfolios based on EDF ranges, firms with EDF values at the ends of the ranges are included in both portfolios. For example, portfolios constructed using the second and third EDF categories have in common all firms with an EDF value exactly equal to $0.52 \%$.
} 
meaningful. Hence, we chose size categories that were sufficiently different to ensure that we captured important relative size differences, but we erred on the side of making the portfolios large enough to provide meaningful empirical results. Note that the asset size categories could not be held constant across the national groups in a meaningful way.

With respect to the portfolios based on both EDF and size categories used in the bivariate analysis, the challenge was to create portfolios whose numbers of credits were approximately uniformly distributed across both sets of categories. However, this task proved impossible given the general dearth of small firms with low EDF values and large firms with high EDF values. Thus, for the bivariate analysis, we collapsed the previous five categories per characteristic into three categories, which generated nine EDF and asset size portfolios for each set of firms. We used the same three EDF categories across the sets of firms, and they were $(0 \%, 0.52 \%],[0.52 \%$, $6.94 \%]$ and $[6.94 \%, 20.00 \%]$. However, the size categories again varied across the sets.

\section{Calibration results}

The calibrated $\bar{\rho}_{\mathrm{A}}$ values are presented below in four subsections corresponding to the aggregate portfolios, univariate analysis of the portfolios constructed using EDF categories, univariate analysis of the portfolios constructed using asset size categories, and bivariate analysis of the portfolios constructed using both EDF and asset size categories. The preliminary empirical results are presented for the $99.5 \%$ and the $99.9 \%$ tail percentiles, which are the two tail percentiles of most common interest. Note that the discussion focuses on the latter percentile since the results are quite similar.

\section{III.A. Calibration results for the aggregate portfolios}

As discussed in Section II.D, we constructed three sets of national firms, as well as the superset of firms, in order to conduct our analysis. Given these four sets of obligors, we

calibrated the $\bar{\rho}_{\mathrm{A}}$ values for the corresponding portfolios. The results are summarized in Table 
2 and Figure 1.

For the "world" portfolio, a total of 13,839 firms were used in the exercise with about $50 \%, 24 \%$ and $26 \%$ being of U.S., Japanese and European origin, respectively. The calibrated $\bar{\rho}_{\mathrm{A}}$ value for this portfolio was relatively low at 0.1125 , potentially suggesting that a single risk factor is not sufficient to capture the heterogenous nature of the credits in the portfolio.

This possibility seems to be reinforced by the differing $\bar{\rho}_{\mathrm{A}}$ values for the three national portfolios. At the $99.9 \%$ percentile, these values are 0.1625 for the U.S. portfolio, 0.2625 for the Japanese portfolio and 0.1375 for the European portfolio. The Japanese value is noticeably higher than the others, probably due to the generally poor economic conditions within Japan at year-end 2000. The European value is relatively low, suggesting that a single factor may not be sufficient to capture the heterogeneity across the five countries that compose that portfolio. The differing values suggest that the degree of heterogeneity across national categories of borrowers may not be well captured by a single risk factor. ${ }^{8}$ In fact, as mentioned earlier, the unconstrained PM model employs over 100 factors.

\section{III.B. Univariate calibration results for portfolios based on EDF categories}

Within the ASRF framework, we expect to see a negative relationship between firm asset correlation and their probabilities of default (PD). That is, as a firm's PD increases due to worsening conditions and its approaching possible default, it is reasonable to think that idiosyncratic factors begin to take on a more important role relative to the common, systematic risk factor. The calibrated $\bar{\rho}_{\mathrm{A}}$ value for the portfolios based on EDF categories support this intuition. These results are presented in Tables 3A through 3D and Figure 2A through 2D. Note

${ }^{8}$ This difficulty is endemic to the ASRF approach. As discussed by Gordy (2001), the use of a single risk factor imposes a common business cycle on all obligors, and all other elements of credit risk are considered to be idiosyncratic. Under this construct, the average asset correlation for a heterogeneous portfolio (such as a collection of firms from a cross-section of countries) should be lower than for a homogenous portfolio with similar characteristics. 
that the results are presented for both the $99.5 \%$ and $99.9 \%$ percentiles, but the discussion focuses on the latter set of results. ${ }^{9}$

For all firms, the results in Table $3 \mathrm{~A}$ and Figure $2 \mathrm{~A}$ indicate that the calibrated $\bar{\rho}_{\mathrm{A}}$ values decline, if only gradually, as the EDF values of the categories increase. For the lowest category, the calibrated $\bar{\rho}_{\mathrm{A}}$ value is 0.1500 , and for the highest category, it is 0.1000 . However, the national portfolios show more variation in this pattern, as shown in Tables 3B through 3D and Figures 2B through 2D.

For the U.S. portfolios, the calibrated $\bar{\rho}_{\mathrm{A}}$ values are higher than the world portfolios, and the slope of the decline is steeper. That is, the decline from the lowest to the highest EDF categories is 0.0750 , as opposed to 0.0500 for the world portfolios. A possible reason for this result is that the world portfolios' greater degree of heterogeneity lessens the impact of the EDF decline on the calibrated $\bar{\rho}_{\mathrm{A}}$ values.

The Japanese portfolios vary the most from the other national portfolios in that the calibrated $\bar{\rho}_{\mathrm{A}}$ values are higher across all EDF categories. The calibrated $\bar{\rho}_{\mathrm{A}}$ values range from 0.3250 to 0.2750 . The decline of about 0.0500 across the categories is in line with the world and European portfolios. Although this decline is also by 0.0500 , the higher levels imply a slighter percentage decline than for the other national portfolios. As mentioned before, the state of the Japanese economy at year-end 2000 was such that less firm heterogeneity in condition was possible, and this circumstance might be better explained by a single factor, even across the EDF categories. In addition, the calibrated $\bar{\rho}_{\mathrm{A}}$ values for the two percentiles are different, with the values for the $99.9 \%$ percentile being higher. ${ }^{10}$

In contrast, the European portfolios have the lowest calibrated $\bar{\rho}_{\mathrm{A}}$ values, ranging from

9 As noted in BCBS (2001c), a potential modification to the Basel II process is a focus on capital requirements set at the $99.9 \%$ percentile rather than the $99.5 \%$ percentile assumed earlier.

10 Note that the $\bar{\rho}_{\mathrm{A}}$ value for the $99.5 \%$ percentile for the lowest EDF category does not fit the expected downward pattern. This result is probably due to the small sample of only 85 firms in that portfolio. Thus, the $\bar{\rho}_{\mathrm{A}}$ value for the $99.9 \%$ percentile is also questionable. 
0.1750 to 0.1250 for the $99.9 \%$ percentile. The decline is even slighter for the $99.5 \%$ percentile, especially given the anomalous 0.1250 value for the lowest EDF category. These lower values are in line with the world portfolio, suggesting that the heterogeneity among the European firms in the sample is also hard to capture with a single, common risk factor.

\section{III.C. Univariate calibration results for portfolios based on asset size categories}

In the general finance theory of portfolio diversification, as the number of different stocks within a portfolio increases, the portfolio becomes more diversified, and the idiosyncratic element of the portfolio's return becomes less important. An analogous view could be taken with respect to a firm's asset size; that is, as a firm becomes larger and comes to contain more assets, it's risk and return characteristics should more closely resemble the overall asset market and be less dependent on the idiosyncratic elements of the individual business lines. Within an ASRF framework, this intuition suggests that a firm's asset correlation should increase as its asset size increases. However, this hypothesis must be verified empirically. In this paper, we tested this hypothesis using firm asset size as the relevant size measure. ${ }^{11}$ The calibration results based on asset size categories are presented in Table 4A through 4D and Figures 3A through 3D.

For the world portfolios based on all the firms in the three national portfolios, the

calibrated $\bar{\rho}_{\mathrm{A}}$ value effectively doubles from 0.1000 for firms smaller than \$20 million to 0.2000 for firms larger than $\$ 1$ billion. The patterns for the national portfolios are similar, but they show certain differences.

For the U.S. portfolio, the calibrated $\bar{\rho}_{\mathrm{A}}$ values actually increase by more, but the rate of increase across the size categories is more gradual. The calibrated $\bar{\rho}_{\mathrm{A}}$ value is 0.1000 for U.S. firms smaller than $\$ 20$ million and effectively triples to 0.3000 for firms larger than $\$ 1$ billion.

\footnotetext{
${ }^{11}$ Note that there are a wide variety of size measures available, such as total sales revenue or number of employees. Further research is necessary to determine the robustness of the presented results to a change in size definition.
} 
As shown in Figure 3B, this increase is approximately linear across the chosen size categories, while the increase for the world portfolio, as shown in Figure 3A, appears to be more exponential in nature. A potential reason for this difference appears to be that the Japanese firms in the world portfolio are generally of larger size than the U.S. firms. As shown in Table 4C, fewer Japanese firms fall into asset size categories less than $\$ 100$ million than U.S. firms. Approximately $20 \%$ of the sample's Japanese firms fall into this category, while about $44 \%$ of U.S. and European firms in the sample fall into these categories. Since firms with assets greater than $\$ 1$ billion make up about $20 \%$ of each of the three national samples, the 24 percentage point difference for the Japanese firms is accounted for by the category of firms between $\$ 100$ million and $\$ 1$ billion in assets.

The calibrated $\bar{\rho}_{\mathrm{A}}$ values for the Japanese portfolios are again higher than those for the world, U.S. and European portfolios. In fact, for these size portfolios, the calibrated $\bar{\rho}_{\mathrm{A}}$ values are relatively much higher, with values of 0.2000 for firms smaller than $\$ 100$ million and 0.4500 for firms larger than $\$ 1$ billion, a multiple of 2.5 across the size categories. As shown in Figure 3C, the increase appears to be more exponential in nature. The Japanese portfolios are clearly different from the U.S. and European portfolios, and hence they are probably contributing greatly to the shape of the increases for the world portfolio.

As before, the calibrated $\bar{\rho}_{\mathrm{A}}$ values for the European firms are generally the lowest of the three aggregate portfolios, ranging from 0.1125 for firms smaller than $\$ 25$ million and 0.2250 for firms larger than $\$ 1$ billion. The doubling of the calibrated $\bar{\rho}_{\mathrm{A}}$ values across the specified size spectrum equals that of the world portfolios and is the lowest of the national portfolios. Note that the pattern of increases, as shown in Figure 3D, again seem to be more exponential than linear.

\section{III.D. Bivariate calibration results for portfolios based on EDF and asset size categories}

The results discussed in the prior two sections indicate that average asset correlations 
within an ASRF framework appear to be a decreasing function of EDF and an increasing function of asset size. In this section, we examine whether calibrated $\bar{\rho}_{\mathrm{A}}$ values are a function of both variables simultaneously. To do so, we formed nine portfolios based on both EDF and asset size categories for the four sets of firms and determined the $\bar{\rho}_{\mathrm{A}}$ values that minimized the dollar difference between the capital requirements for the unconstrained PM model and the constrained ASRF version. ${ }^{12}$

The calibration results suggest three key outcomes. First, as in the univariate results, the calibrated average asset correlations are generally decreasing functions of EDF and increasing functions of asset size. Thus, both of the these univariate results are important to consider. Second, the increases in the calibrated average asset correlation with respect to increases in size appear to be larger than the decreases with respect to increasing EDF values. In other words, the marginal impact on a calibrated $\bar{\rho}_{\mathrm{A}}$ of an increase in firm asset size appears to be larger than the marginal impact of an increase in firm EDF value. Third, the changes in the calibrated $\bar{\rho}_{\mathrm{A}}$ values across EDF categories appear to become greater as firm asset size increases. That is, as firms get larger, changes in EDF lead to larger changes in firm sensitivity to the common risk factor. A further result is that the $\bar{\rho}_{\mathrm{A}}$ level rankings across the four aggregate portfolios remain the same as for the univariate results. However, this result may not be surprising given that the data sample period of year-end 2000 is the same.

Two important caveats regarding the calibration results in this section should be noted. First, the analysis was conducted using discrete EDF and size categories and not using continuous functions. Hence, any inference on $\bar{\rho}_{\mathrm{A}}$ changes across the categories is relatively limited and cannot be easily tested. However, the general patterns of variation that are observed should provide reasonably suggestive evidence. Second, the number of firms in the portfolios varies and can be quite low in the extreme categories, such as the largest firms with highest EDF

\footnotetext{
12 Note that as before, the EDF categories are common across the three national portfolios and the world portfolio, but the asset size categories vary.
} 
values and the smallest firms with lowest EDF values. These data limitations are endemic to this type of analysis and can effectively be seen as increasing the standard errors around the calibrated $\bar{\rho}_{\mathrm{A}}$ values for those portfolios. This larger degree of uncertainty obviously limits the inference that can be drawn from the results. However, the general patterns discussed here should be robust since they are also observed for portfolios that have reasonable numbers of observations.

Turning to the results, the calibrated $\bar{\rho}_{\mathrm{A}}$ values for the nine world portfolios are presented in Table 5A and Figure 4A. Note that the values for the first two size categories do not vary across the EDF categories, but they do decline for the third category, as previously observed. The reasons for the constant $\bar{\rho}_{\mathrm{A}}$ values across the EDF categories are not clear, but this result could be indicative that firm size is a potentially important factor in determining average asset correlations. Looking across asset size categories for a given EDF category, we observe that the calibrated $\bar{\rho}_{\mathrm{A}}$ values increase with size, as per the univariate results. For these portfolios, variation in asset size clearly has a greater impact on the calibrated $\bar{\rho}_{\mathrm{A}}$ values than variation in EDF values.

The calibrated $\bar{\rho}_{\mathrm{A}}$ values for the nine U.S. portfolios are presented in Table 5B and Figure 4B. These values range from 0.1375 to 0.3250 . Overall, these $\bar{\rho}_{\mathrm{A}}$ values are higher than the values for the world portfolio, possibly indicating that national portfolio diversification issues could impact the average asset correlations. The univariate patterns previously observed are apparent in the bivariate analysis as well. Looking across the categories, the calibrated $\bar{\rho}_{\mathrm{A}}$ values decrease from the lowest to the highest EDF categories within a given size category by roughly 0.1000 , whereas the $\bar{\rho}_{\mathrm{A}}$ values approximately double from the smallest to the largest size category within a given EDF category. This result further suggests the importance of firm size in determining a portfolio's average asset correlation.

The calibrated $\bar{\rho}_{\mathrm{A}}$ values for the Japanese portfolios are presented in Table 5C and Figure 4C. As noted before, the $\bar{\rho}_{\mathrm{A}}$ values for these portfolios are substantially higher than those of the other national portfolios. The values range from 0.2000 to 0.5500 , although this 
latter value for the portfolio with the largest firms and the highest EDF values is based on a sample of just 64 firms (or just $2 \%$ of the Japanese sample). Although the pattern of declining $\bar{\rho}_{\mathrm{A}}$ values within a size category due to increasing EDF values is not apparent here, the $\bar{\rho}_{\mathrm{A}}$ values do increase with asset size for a given EDF category. In fact, the size effect is strongest for the Japanese results.

The calibrated $\bar{\rho}_{\mathrm{A}}$ values for the European portfolios are presented in Table $5 \mathrm{D}$ and Figure 4D. The values here range from 0.1250 to 0.2000 . Note that these values do not vary much across either EDF or asset size categories. In fact, $\bar{\rho}_{\mathrm{A}}=0.1250$ for all EDF categories across the first two asset size categories. Only for the largest EDF category do we observe an increase in $\bar{\rho}_{\mathrm{A}}$ across the size categories and a decline across the EDF categories. This relative lack of $\bar{\rho}_{\mathrm{A}}$ variation is approximately similar to the univariate results, but further analysis is needed here.

In conclusion, the analysis of the calibrated $\bar{\rho}_{\mathrm{A}}$ values using an ASRF framework within the KMV methodology provides strong suggestive evidence that both EDF values and firm size are important driving factors. In addition, the results also suggest national characteristics are potentially important, but more analysis over other time periods is necessary to verify this result.

\section{Regulatory Values for Average Asset Correlation}

In an effort to update and improve international bank capital requirements, the BCBS began a revision of the 1988 Basel Accord in 1999, a process that has come to be known as "Basel II". A primary goal of the Basel II process is to make credit risk capital requirements more risk-sensitive; i.e., more closely linked to the economic risks faced by banks in their business activities. Credit risk modeling is to play an important role in this process.

As detailed in BCBS (2001a), the BCBS decided to adopt an evolutionary approach to the implementation of credit risk capital requirements, an approach that mirrors the evolution of 
credit risk management techniques themselves. ${ }^{13}$ For banks that do not have sufficiently well developed credit risk models, credit risk capital requirements are to be determined using the "standardized" approach, which effectively does not require modeling input from the banks. However, for banks that are employing more quantitatively oriented techniques of credit risk management, particularly internal risk-rating systems, an internal-ratings based (IRB) approach was proposed.

The IRB approach has two tiers within it. The first tier, known as the "foundation" IRB approach, permits banks to input their own credit risk assessments of their lending portfolios, but estimation of additional inputs are derived through the application of standardized regulatory rules. This IRB approach is intended to be used by banks that currently face difficulty in estimating certain risk model parameters due to data limitations or less-developed credit risk models. The second tier, known as the "advanced" IRB approach, would allow banks to use their own internal credit risk modeling outcomes to establish their regulatory credit risk capital requirements.

As mentioned earlier, the analytical framework used for determining credit risk capital requirements within the Basel II process is the ASRF framework described by Gordy (2001). Within this framework, as discussed in section II, the average asset correlation $\bar{\rho}_{\mathrm{A}}$ is a key parameter, but regulators need only specify a value for it for the foundation IRB approach. In paragraph 172 of the January 2001 proposal (BCBS, 2001a), the regulatory value of $\bar{\rho}_{A}$ was set to be constant at 0.2000 , based on surveys of industry practice and research conducted by the BCBS.

This assumption, as well as the various others that compose the IRB approach, were examined within the context of two quantitative impact studies; the second of which, known as QIS-2, was initiated in April 2001 and summarized in BCBS (2001c). In light of those results,

13 For a survey of the credit risk modeling at large financial institutions, see BCBS (1999). See Hirtle et.al (2001) for a discussion of the policy options for using such models for regulatory purposes, 
the BCBS initiated a more targeted study of the foundation IRB approach in November 2001, which is known as QIS-2.5; see BCBS (2001b). ${ }^{14}$ Within this study, the asset correlation assumption was modified to make $\rho_{\mathrm{A}}$ a function of the probability of default (PD). Specifically,

$$
\rho_{\mathrm{A}}(\mathrm{PD})=0.10\left(\frac{1-\mathrm{e}^{-50 * \mathrm{PD}}}{1-\mathrm{e}^{-50}}\right)+0.20\left(1-\frac{1-\mathrm{e}^{-50 * \mathrm{PD}}}{1-\mathrm{e}^{-50}}\right) \text {, }
$$

or equivalently,

$$
\rho_{\mathrm{A}}(\mathrm{PD})=0.2-0.1\left(\frac{1-\mathrm{e}^{-50 * \mathrm{PD}}}{1-\mathrm{e}^{-50}}\right)
$$

See Figure 5 for a graphical presentation of this function.

In this section, we further analyze our calibrated $\bar{\rho}_{\mathrm{A}}$ values with respect to both the proposed January and November regulatory $\bar{\rho}_{\mathrm{A}}$ values. Specifically, the calibrated $\bar{\rho}_{\mathrm{A}}$ values are compared to the assumption that $\bar{\rho}_{\mathrm{A}}=0.2000$ and to the November proposal evaluated at the mean, median and maximum EDF values of the constructed portfolios. Note that only the median results will be addressed directly. The results are presented in Tables 6 through 9 and Figures 6 through 9.

These results suggest five key outcomes. First, the overall comparison of the calibrated $\bar{\rho}_{\mathrm{A}}$ values and the January proposal suggests that there is sufficient variation as to make the constant assumption too inaccurate. Second, the overall comparison of the calibrated $\bar{\rho}_{\mathrm{A}}$ values and the November proposal are rather favorable, especially for higher EDF categories and more diversified portfolios. However, there are important areas of difference. Third, limitation to a maximum $\rho_{A}(\mathrm{PD})$ value of 0.2000 is not warranted by the calibration results. Fourth, the decline in $\rho_{A}(P D)$ due to increases in PD values is quicker than suggested by the calibrated $\bar{\rho}_{\mathrm{A}}$ values.

\footnotetext{
14 The BCBS clearly states that it "has not at this stage endorsed the specific modifications that are the focus of the additional quantitative impact exercise."
} 
Fifth, the formula in the November proposal does not account for size, and the greatest deviations from the calibrated $\bar{\rho}_{\mathrm{A}}$ values are for the larger firms, suggesting the potential value of incorporating some element of firm size into the regulatory values for average asset correlations.

\section{IV.A. Comparison for aggregate portfolios}

The comparison of the calibrated $\bar{\rho}_{\mathrm{A}}$ values for the four aggregate portfolios with the November regulatory values is presented in Table 6 and Figure 5. Overall, the calibrated $\bar{\rho}_{\mathrm{A}}$ values are not that different, with the exception of the Japanese portfolio. The calibrated $\bar{\rho}_{\mathrm{A}}$ value for this portfolio is 0.2625 , while the November regulatory proposal suggests a value of 0.1430 , which is more in line with the value for the regulatory values of the other three portfolios. These results suggest that for broadly diversified portfolios, the November proposal for regulatory $\bar{\rho}_{\mathrm{A}}$ values appears to match the calibration results quite well, although country concentrations may be a concern.

\section{IV.B. Comparison for portfolios based on EDF categories}

The comparison of calibrated $\bar{\rho}_{\mathrm{A}}$ values for the portfolios based on EDF categories with the November regulatory proposal evaluated at the portfolio medians is presented in Tables 7A through 7D and Figure 6. Overall, the differences between these alternative $\bar{\rho}_{\mathrm{A}}$ values is relatively small, again except for the Japanese portfolios. Using the metric that deviations of \pm 0.05 are reasonable, the calibrated $\bar{\rho}_{\mathrm{A}}$ values for the world, U.S. and European portfolios are well represented by the November regulatory values. The calibrated $\bar{\rho}_{A}$ values for the Japanese portfolio range from 0.2500 to 0.3250 , all of which exceed the maximum regulatory value. Note that several U.S. portfolios with smaller median EDF values also have calibrated $\bar{\rho}_{\mathrm{A}}$ values above 0.2000 .

Another interesting point of comparison is the speed with which the alternative $\bar{\rho}_{\mathrm{A}}$ 
values decline as EDF increases. Of course, the alternative measures are difficult to compare since one is calibrated for select EDF ranges and the other is a continuous PD function.

However, the comparative results in Table 7 suggest that the regulatory $\bar{\rho}_{\mathrm{A}}$ values decline at a slightly faster rate than suggested by the calibrated $\bar{\rho}_{\mathrm{A}}$ values.

\section{IV.C. Comparison for portfolios based on asset size categories}

The comparison between the calibrated $\bar{\rho}_{\mathrm{A}}$ values for the portfolios based on asset size categories and the values from the November regulatory proposal evaluated at the portfolio medians is presented in Tables $8 \mathrm{~A}$ through $8 \mathrm{D}$ and Figure 7. As the November proposal does not incorporate a measure of firm size, the regulatory $\bar{\rho}_{\mathrm{A}}$ values in this table do not account for the size variation across portfolios. However, they increase across the size categories, as observed in previous sections, because the median EDF values of the portfolios also increase with asset size.

Overall, the differences between the alternative $\bar{\rho}_{\mathrm{A}}$ values is relatively small (i.e., within a range of \pm 0.05 ), with the main exception of the Japanese portfolios. As before, the Japanese calibrated $\bar{\rho}_{\mathrm{A}}$ values are much larger than the regulatory $\bar{\rho}_{\mathrm{A}}$ values, with differences ranging from 0.07 to 0.28 . Another exception was the second size category for the European portfolios, and two further exceptions were observed here for the two largest categories of U.S. firms. The calibrated values exceeded the regulatory maximum value and had differences of more than 0.05. Thus, although the regulatory values are quite similar to the calibrated values, the U.S. exceptions could suggest that important deviations due to firm size, especially for large firms, may be a concern.

\section{IV.D. Comparison for portfolios based on EDF and asset size categories}

The comparison of calibrated $\bar{\rho}_{\mathrm{A}}$ values for the portfolios based on EDF and asset size categories with the regulatory values based on the November proposal evaluated at the portfolio medians is presented in Tables 9A through 9D and Figures 9A through 9D. As before, the 
regulatory $\bar{\rho}_{\mathrm{A}}$ values increase across the asset size categories for a given EDF category because of the increasing median EDF values, but these increases are moderated relative to the results in Table 8 due to the smaller sample sizes in the bivariate analysis.

Overall, the differences between the alternative measures are once again relatively small; i.e., within \pm 0.05 . Of the 36 portfolios examined, the absolute difference in $\bar{\rho}_{\mathrm{A}}$ values was greater than 0.05 for $47 \%$ of the cases and just $37 \%$ when the Japanese portfolios are excluded. The deviations were largest for firms in the largest size categories, which accounted for $50 \%$ of the deviations excluding the Japanese portfolios. These results suggest that the calibrated $\bar{\rho}_{\mathrm{A}}$ values deviate most from the regulatory values, which do not take size into account, for the largest firms in the four firm samples.

The results in Table 9 show that the speeds with which the alternative $\bar{\rho}_{\mathrm{A}}$ values decline as the EDF values increases are quite different. Within an asset size category, the calibrated $\bar{\rho}_{\mathrm{A}}$ values generally either remain constant or decline moderately as the median EDF values increase across the EDF categories, again with the exception of the Japanese portfolios. However, for the regulatory $\bar{\rho}_{\mathrm{A}}$ values, the values start near the maximum value of 0.2000 for the lowest EDF category and quickly dive to the minimum value of 0.1000 . Thus, by ignoring firm asset size, the regulatory proposal causes greater $\bar{\rho}_{\mathrm{A}}$ variability than is suggested by the calibrated $\bar{\rho}_{\mathrm{A}}$ values. These results further suggest that a consideration of firm asset size in the calculation of the regulatory $\bar{\rho}_{\mathrm{A}}$ values, especially for larger firms, could be warranted.

\section{Conclusion}

The asymptotic single risk factor (ASRF) approach is a simplifying framework for determining regulatory capital charges for credit risk. As described by Gordy (2001), this framework has become the basis upon which the credit risk capital charges for the second Basel Accord are being determined. In this paper, the ASRF approach was imposed on the KMV methodology for determining credit risk capital charges in order to examine the relationship 
between average asset correlation, firm probability of default and firm asset size measured by the book value of assets. The analysis was conducted on national portfolios of American, Japanese and European firms, as well as a world portfolio composed of the three national portfolios, using data from year-end 2000 .

The univariate calibration results indicate that average asset correlation is a decreasing function of the probability of default. This univariate result suggests that the reasons why firms experience rising default probabilities are mainly idiosyncratic and not as closely tied to the general economic environment summarized by the single, common factor. The empirical results further indicate that average asset correlation is increasing in asset size. That is, as firms increase the book value of their assets, they become more correlated with the general economic environment and the common factor. This result is intuitive in the sense that larger firms can generally be viewed as portfolios of smaller firms, and such portfolios would be relatively more sensitive to common risks than to idiosyncratic risks.

The bivariate calibration results support both sets of univariate results and appear to highlight an additional and potentially important relationship between the three variables. The decreasing relationship between average asset correlation and default probability is more pronounced for larger firms. In other words, the average asset correlation for larger firms is more sensitive to firm probability of default than it is for smaller firms. These results provide evidence that both default probability and firm size impact average asset correlation within an ASRF framework, especially for larger firms. Hence, further work regarding whether regulatory capital requirements should take account of other factors seem warranted.

In this paper, we also compared the calibration results with the formula for the average asset correlation proposed by the BCBS in November 2001. This formula explicitly makes the average asset correlation a function of firm probability of default. Based on the regulatory formula, the deviations between the calibrated and regulatory $\bar{\rho}_{\mathrm{A}}$ values that are greatest are for the larger firms, suggesting the potential value of incorporating firm size into the regulatory 
average asset correlation formula.

These calibration results provide suggestive evidence that firm size is an important variable in determining credit risk capital requirements and may need to be accounted for in the regulatory calculations within the Basel II process. However, the limitations to these calibration results, such as the simple maturity and granularity assumptions, must be considered in light of all the elements of the Basel II credit risk capital requirements, and the final regulatory capital requirements may not need to explicitly account for these relationships within the average asset correlation. 


\section{References}

Basel Committee on Banking Supervision, 1999. "Credit Risk Modeling: Current Practices and Applications," Technical report, Bank for International Settlements.

Basel Committee on Banking Supervision, 2001a. "The Internal Ratings-Based Approach: Supporting Document to the New Basel Capital Accord," Consultative document.

Basel Committee on Banking Supervision, 2001b. "Results of the Second Quantitative Impact Study," Press release dated November 5, 2001.

Basel Committee on Banking Supervision, 2001c. "Potential Modification to the Committee's Proposals," Press release dated November 5, 2001.

Crosbie, P.J. and Bohn, J.R., 2001. "Modeling Default Risk,” Manuscript, KMV LLC. (http://www.kmv.com/Knowledge_Base/public/cm/white/Modeling_Default_Risk.pdf)

Gordy, M.B., 2000a. "A Comparative Anatomy of Credit Risk Models," Journal of Banking and Finance, 24, 119-149.

Gordy, M.B., 2000b. "Credit VAR and Risk-Bucket Capital Rules: A Reconciliation," in Proceedings of the $36^{\text {th }}$ Annual Conference on Bank Structure and Competition, 406-415.

Gordy, M.B., 2001. "A Risk-Factor Model Foundation for Ratings-Based Bank Capital Rules," Manuscript, Board of Governors of the Federal Reserve System.

Hirtle, B., Levonian, M., Saidenberg, M., Walter, S. and Wright, D., 2001. "Using Credit Risk Models for Regulatory Capital: Issues and Options," Federal Reserve Bank of New York Economic Policy Review, March, 19-36. 
Table 1. The Mapping of S\&P Credit Ratings to KMV EDF Values

\begin{tabular}{|c|c|}
\hline S\&P Rating & KMV EDF value (\%) \\
\hline AAA & $(0.00,0.02]$ \\
\hline $\mathrm{AA}^{+}$ & $(0.02,0.03]$ \\
\hline AA & $(0.03,0.04]$ \\
\hline $\mathrm{AA}^{-}$ & $(0.04,0.05]$ \\
\hline $\mathrm{A}^{+}$ & $(0.05,0.07]$ \\
\hline A & $(0.07,0.09]$ \\
\hline $\mathrm{A}^{-}$ & $(0.09,0.14]$ \\
\hline $\mathrm{BBB}^{+}$ & $(0.14,0.21]$ \\
\hline BBB & $(0.21,0.31]$ \\
\hline $\mathrm{BBB}^{-}$ & $(0.31,0.52]$ \\
\hline $\mathrm{BB}^{+}$ & $(0.52,0.86]$ \\
\hline BB & $(0.86,1.43]$ \\
\hline $\mathrm{BB}^{-}$ & $(1.43,2.03]$ \\
\hline $\mathrm{B}^{+}$ & $(2.03,2.88]$ \\
\hline $\mathrm{B}$ & $(2.88,4.09]$ \\
\hline $\mathrm{B}^{-}$ & $(4.09,6.94]$ \\
\hline $\mathrm{CCC}^{+}$ & $(6.94,11.78]$ \\
\hline $\mathrm{CCC}$ & $(11.78,14.00]$ \\
\hline $\mathrm{CCC}^{-}$ & $(14.00,16.70]$ \\
\hline $\mathrm{CC}$ & $(16.70,17.00]$ \\
\hline $\mathrm{C}$ & $(17.00,18.25]$ \\
\hline $\mathrm{D}$ & $(18.25,20.00]$ \\
\hline
\end{tabular}

Note: This mapping is derived from KMV Credit Monitor ${ }^{\odot}$, version 3.4i, and based on year-end 2000 data. 
Table 2. Calibrated Average Asset Correlations for Aggregate Portfolios

\begin{tabular}{|l|c|c|c|}
\hline \multirow{2}{*}{\multicolumn{1}{|c|}{ Portfolio }} & Number of firms & \multicolumn{2}{c|}{ Calibrated Average Asset Correlations } \\
\cline { 3 - 4 } & 13,839 & $\mathbf{9 9 . 5 \%}$ percentile & $\mathbf{9 9 . 9 \%}$ percentile \\
\hline All firms & 6,909 & 0.1125 & 0.1125 \\
\hline \hline U.S. firms & 3,255 & 0.1625 & 0.1625 \\
\hline Japanese firms & 3,675 & 0.2625 & 0.2625 \\
\hline European firms & 0.1250 & 0.1375 \\
\hline
\end{tabular}

The portfolio of all firms contains all of the U.S., Japanese and European firms in the KMV CreditMonitor database as of year-end 2000.

European firms are defined here as firms headquartered in France, Germany, Great Britain, Italy and the Netherlands. Note that U.S., Japanese and European firms make up 50\%, 24\% and 26\%, respectively, of all the firms examined here. 
Table 3A. Calibrated Average Asset Correlations for World Portfolios based on EDF Categories

\begin{tabular}{|c|c|c|c|}
\hline \multirow{2}{*}{ EDF categories $(\boldsymbol{\%})$} & Number of firms & $\mathbf{2}$ Calibrated Average Asset Correlations \\
\cline { 3 - 4 } & 644 & 0.1500 & 0.1500 \\
\hline $\mathbf{( 0 . 0 0 , 0 . 0 5 ]}$ & 3,478 & 0.1500 & 0.1500 \\
\hline$[\mathbf{0 . 0 5}, \mathbf{0 . 5 2}]$ & 3,711 & 0.1250 & 0.1250 \\
\hline$[\mathbf{0 . 5 2 , 2 . 0 3 ]}$ & 3,034 & 0.1125 & 0.1125 \\
\hline$[\mathbf{2 . 0 3}, \mathbf{6 . 9 4}]$ & 3,148 & 0.1000 & 0.1000 \\
\hline$[\mathbf{6 . 9 4 , 2 0 . 0 0 ]}$ & 14,015 & & \\
\hline & & & \\
\hline
\end{tabular}

The total number of firms in the world portfolios based on EDF categories is 14,015, which is more than the 13,839 firms reported in Table 2. The difference of 176 firms is due to firms with EDF values of exactly $0.05 \%, 0.52 \%, 2.03 \%$ and $6.94 \%$ being included in two different portfolios each.

Table 3B. Calibrated Average Asset Correlations for U.S. Portfolios based on EDF Categories

\begin{tabular}{|c|c|c|c|}
\hline & & \multicolumn{2}{|c|}{ Calibrated Average Asset Correlations } \\
\cline { 3 - 4 } EDF categories $(\%)$ & Number of firms & $\mathbf{9 9 . 5 \%}$ percentile & $\mathbf{9 9 . 9 \%}$ percentile \\
\hline $\mathbf{( 0 . 0 0 , 0 . 0 5 ]}$ & 131 & 0.2250 & 0.2250 \\
\hline$[\mathbf{0 . 0 5 , 0 . 5 2 ]}$ & 1,567 & 0.2250 & 0.2500 \\
\hline$[\mathbf{0 . 5 2}, \mathbf{2 . 0 3}]$ & 1,798 & 0.2000 & 0.2000 \\
\hline$[\mathbf{2 . 0 3 , 6 . 9 4 ]}$ & 1,437 & 0.1750 & 0.1750 \\
\hline$[\mathbf{6 . 9 4 ,} \mathbf{2 0 . 0 0 ]}$ & 2,475 & 0.1500 & 0.1500 \\
\hline & 7,408 & & \\
\hline
\end{tabular}

The total number of firms in the U.S. portfolios based on EDF categories is 7,408, which is more than the 6,909 U.S. firms reported in Table 2. The difference of 499 firms is due to firms with EDF values of exactly $0.05 \%, 0.52 \%, 2.03 \%$ and $6.94 \%$ being included in two different portfolios each. 
Table 3C. Calibrated Average Asset Correlations for Japanese Portfolios based on EDF Categories

\begin{tabular}{|c|c|c|c|}
\hline \multirow{2}{*}{ EDF categories $(\%)$} & Calibrated Average Asset Correlations \\
\cline { 3 - 4 } & Number of firms & $\mathbf{9 9 . 5 \%}$ percentile & $\mathbf{9 9 . 9 \%}$ percentile \\
\hline $\mathbf{( 0 . 0 0 , 0 . 0 5 ]}$ & 85 & 0.2000 & 0.3250 \\
\hline$[\mathbf{0 . 0 5 , \boldsymbol { 0 . 5 2 } ]}$ & 748 & 0.3000 & 0.3250 \\
\hline$[\mathbf{0 . 5 2 , \boldsymbol { 2 . 0 3 } ]}$ & 1,020 & 0.2750 & 0.2750 \\
\hline$[\mathbf{2 . 0 3 , 6 . 9 4 ]}$ & 994 & 0.2500 & 0.2500 \\
\hline$[\mathbf{6 . 9 4 , \mathbf { 2 0 . 0 0 } ]}$ & 499 & 0.2500 & 0.2750 \\
\hline & 3,346 & & \\
\hline
\end{tabular}

The total number of firms in the Japanese portfolios based on EDF categories is 3,346, which is more than the 3,255 Japanese firms reported in Table 2. The difference of 91 firms is due to firms with EDF values of exactly $0.05 \%, 0.52 \%, 2.03 \%$ and $6.94 \%$ being included in two different portfolios each.

Table 3D. Calibrated Average Asset Correlations for European Portfolios based on EDF Categories

\begin{tabular}{|c|c|c|c|}
\hline & & \multicolumn{2}{|c|}{ Calibrated Average Asset Correlations } \\
\cline { 3 - 4 } EDF categories $(\boldsymbol{\%})$ & Number of firms & $\mathbf{9 9 . 5 \%}$ percentile & $\mathbf{9 9 . 9 \%}$ percentile \\
\hline $\mathbf{( 0 . 0 0 , \boldsymbol { 0 . 0 5 } ]}$ & 457 & 0.1250 & 0.1750 \\
\hline$[\mathbf{0 . 0 5 , \boldsymbol { 0 . 5 2 } ]}$ & 1,299 & 0.1500 & 0.1750 \\
\hline$[\mathbf{0 . 5 2}, \mathbf{2 . 0 3}]$ & 1,024 & 0.1500 & 0.1500 \\
\hline$[\mathbf{2 . 0 3 , 6 . 9 4 ]}$ & 714 & 0.1250 & 0.1250 \\
\hline$[\mathbf{6 . 9 4 ,} \mathbf{2 0 . 0 0 ]}$ & 486 & 0.1250 & 0.1250 \\
\hline & 3,980 & & \\
\hline
\end{tabular}

The total number of firms in the European portfolios based on EDF categories is 3,980, which is more than the 3,675 European firms reported in Table 2. The difference of 305 firms is due to firms with EDF values of exactly $0.05 \%, 0.52 \%, 2.03 \%$ and $6.94 \%$ being included in two different portfolios each. 
Table 4A. Calibrated Average Asset Correlations

for World Portfolios based on Asset Size Categories

\begin{tabular}{|c|c|c|c|}
\hline \multirow[b]{2}{*}{ Asset size categories } & \multirow[b]{2}{*}{ Number of firms } & \multicolumn{2}{|c|}{ Calibrated Average Asset Correlations } \\
\hline & & 99.5\% percentile & 99.9\% percentile \\
\hline$(\$ 0, \$ 20 \mathrm{~m}]$ & 2,103 & 0.1000 & 0.1000 \\
\hline$[\$ 20 \mathrm{~m}, \$ 100 \mathrm{~m}]$ & 3,230 & 0.1000 & 0.1000 \\
\hline$[\$ 100 \mathrm{~m}, \$ 300 \mathrm{~m}]$ & 3,031 & 0.1125 & 0.1125 \\
\hline$[\$ 300 \mathrm{~m}, \$ 1,000 \mathrm{~m}]$ & 2,706 & 0.1375 & 0.1375 \\
\hline \multirow[t]{2}{*}{$\geq \$ 1,000 \mathrm{~m}$} & 2,969 & 0.2000 & 0.2000 \\
\hline & 14,039 & & \\
\hline
\end{tabular}

The total number of firms in the world portfolios based on asset size categories is 14,039 , which is more than the 13,839 firms reported in Table 2. The difference of 200 firms is due to firms with asset size values of exactly $\$ 20 \mathrm{~m}, \$ 100 \mathrm{~m}, \$ 300 \mathrm{~m}$ and $\$ 1,000 \mathrm{~m}$ being included in two different portfolios each.

Table 4B. Calibrated Average Asset Correlations for U.S. Portfolios based on Asset Size Categories

\begin{tabular}{|c|c|c|c|}
\hline \multirow[b]{2}{*}{ Asset size categories } & \multirow[b]{2}{*}{ Number of firms } & \multicolumn{2}{|c|}{ Calibrated Average Asset Correlations } \\
\hline & & 99.5\% percentile & 99.9\% percentile \\
\hline$(\$ 0, \$ 20 \mathrm{~m}]$ & 1,515 & 0.1250 & 0.1000 \\
\hline$[\$ 20 \mathrm{~m}, \$ 100 \mathrm{~m}]$ & 1,655 & 0.1500 & 0.1500 \\
\hline$[\$ 100 \mathrm{~m}, \$ 300 \mathrm{~m}]$ & 1,330 & 0.1750 & 0.1750 \\
\hline$[\$ 300 \mathrm{~m}, \$ 1,000 \mathrm{~m}]$ & 1,336 & 0.2250 & 0.2250 \\
\hline \multirow[t]{2}{*}{$\geq \$ 1,000 \mathrm{~m}$} & 1,543 & 0.2750 & 0.3000 \\
\hline & 7,374 & & \\
\hline
\end{tabular}

The total number of firms in the U.S. portfolios based on asset size categories is 7,374, which is more than the 6,909 U.S. firms reported in Table 2. The difference of 465 firms is due to firms with asset sizes values of exactly $\$ 20 \mathrm{~m}, \$ 100 \mathrm{~m}, \$ 300 \mathrm{~m}$ and $\$ 1,000 \mathrm{~m}$ being included in two different portfolios each. 
Table 4C. Calibrated Average Asset Correlations for Japanese Portfolios based on Asset Size Categories

\begin{tabular}{|c|c|c|c|}
\hline \multirow[b]{2}{*}{ Asset size categories } & \multirow[b]{2}{*}{ Number of firms } & \multicolumn{2}{|c|}{ Calibrated Average Asset Correlations } \\
\hline & & $99.5 \%$ percentile & 99.9\% percentile \\
\hline$(\$ 0, \$ 100 \mathrm{~m}]$ & 643 & 0.2000 & 0.2000 \\
\hline$[\$ 100 \mathrm{~m}, \$ 200 \mathrm{~m}]$ & 658 & 0.2000 & 0.2000 \\
\hline$[\$ 200 \mathrm{~m}, \$ 400 \mathrm{~m}]$ & 633 & 0.2500 & 0.2500 \\
\hline$[\$ 400 \mathrm{~m}, \$ 1,000 \mathrm{~m}]$ & 606 & 0.3000 & 0.3000 \\
\hline \multirow[t]{2}{*}{$\geq \$ 1,000 \mathrm{~m}$} & 771 & 0.4250 & 0.4500 \\
\hline & 3,311 & & \\
\hline
\end{tabular}

The total number of firms in the Japanese portfolios based on asset size categories is 3,311, which is more than the 3,255 Japanese firms reported in Table 2. The difference of 56 firms is due to firms with asset size values of exactly $\$ 100 \mathrm{~m}, \$ 200 \mathrm{~m}, \$ 400 \mathrm{~m}$ and $\$ 1,000 \mathrm{~m}$ being included in two different portfolios each.

Table 4D. Calibrated Average Asset Correlations for European Portfolios based on Asset Size Categories

\begin{tabular}{|c|c|c|c|}
\hline \multirow[b]{2}{*}{ Asset size categories } & \multirow[b]{2}{*}{ Number of firms } & \multicolumn{2}{|c|}{ Calibrated Average Asset Correlations } \\
\hline & & 99.5\% percentile & 99.9\% percentile \\
\hline$(\$ 0, \$ 25 \mathrm{~m}]$ & 948 & 0.1125 & 0.1125 \\
\hline$[\$ 25 \mathrm{~m}, \$ 75 \mathrm{~m}]$ & 778 & 0.1125 & 0.1125 \\
\hline$[\$ 75 \mathrm{~m}, \$ 200 \mathrm{~m}]$ & 705 & 0.1250 & 0.1250 \\
\hline$[\$ 200 \mathrm{~m}, \$ 1,000 \mathrm{~m}]$ & 782 & 0.1500 & 0.1500 \\
\hline \multirow[t]{2}{*}{$\geq \$ 1,000 \mathrm{~m}$} & 693 & 0.2250 & 0.2250 \\
\hline & 3,906 & & \\
\hline
\end{tabular}

The total number of firms in the European portfolios based on asset size categories is 3,906, which is more than the 3,675 European firms reported in Table 2. The difference of 231 firms is due to firms with asset sizes values of exactly $\$ 25 \mathrm{~m}, \$ 75 \mathrm{~m}, \$ 200 \mathrm{~m}$ and $\$ 1,000 \mathrm{~m}$ being included in two different portfolios each. 
Table 5A1. The Number of Firms in the World Portfolios based on EDF and Asset Size Categories

\begin{tabular}{|c|c|c|c|c|}
\hline \multirow{2}{*}{ Asset size categories } & \multicolumn{3}{|c|}{ EDF categories (\%) } & \multirow{2}{*}{} \\
\cline { 2 - 5 } & $\mathbf{( 0 . 0 0 , 0 . 5 2}]$ & {$[\mathbf{0 . 5 2}, \mathbf{6 . 9 4}]$} & {$[\mathbf{6 . 9 4 ,} \mathbf{2 0 . 0 0 ]}$} & \\
\hline $\mathbf{( \$ 0 m , ~ \$ 7 5 m ]}$ & 675 & 2,126 & 1,840 & 4,641 \\
\hline [\$75m, \$500m] & 1,281 & 2,754 & 929 & 4,964 \\
\hline$\geq \mathbf{\$ 5 0 0 m}$ & 2,065 & 1,846 & 379 & 4,290 \\
\hline & 4,021 & 6,726 & 3,148 & 13,895 \\
\hline
\end{tabular}

The total number of firms in the world portfolios based on EDF and asset size categories is 13,895, which is more than the 13,839 firms reported in Table 2. The difference of 56 firms is due to firms with EDF or asset size values that fall at a range's endpoints being included in more than one portfolio.

Table 5A2. Calibrated Average Asset Correlations at the 99.9\% Percentile for the World Portfolios based on EDF and Asset Size Categories

\begin{tabular}{|c|c|c|c|}
\hline \multirow{2}{*}{ Asset size categories } & \multicolumn{3}{|c|}{ EDF categories (\%) } \\
\cline { 2 - 4 } & $\mathbf{( 0 . 0 0 , 0 . 5 2 ]}$ & {$[\mathbf{0 . 5 2}, \mathbf{6 . 9 4}]$} & {$[\mathbf{6 . 9 4 ,}, \mathbf{2 0 . 0 0 ]}$} \\
\hline $\mathbf{( \$ 0 m , ~ \$ 7 5 m ]}$ & 0.1000 & 0.1000 & 0.1000 \\
\hline$[\mathbf{\$ 7 5 m}, \mathbf{\$ 5 0 0 m}]$ & 0.1125 & 0.1125 & 0.1125 \\
\hline$\geq \$ \mathbf{5 0 0 m}$ & 0.2000 & 0.1750 & 0.1625 \\
\hline
\end{tabular}

The table reports the average asset correlations for the nine world portfolios calibrated to the $99.9 \%$ percentile of the portfolio value distributions. Unless otherwise noted, the average asset correlations calibrated to the $99.5 \%$ percentile are identical. For the world portfolio with the second asset size category and the second EDF category, the average asset correlation calibrated to the $99.5 \%$ percentile is 0.1250 . 
Table 5B1. The Number of Firms in the U.S. Portfolios based on EDF and Asset Size Categories

\begin{tabular}{|c|c|c|c|c|}
\hline \multirow{2}{*}{ Asset size categories } & \multicolumn{3}{|c|}{ EDF categories (\%) } & \\
\hline & $(0.00,0.52]$ & {$[0.52,6.94]$} & {$[6.94,20.00]$} & \\
\hline$(\$ 0 \mathrm{~m}, \$ 100 \mathrm{~m}]$ & 230 & 1,214 & 1,734 & 3,178 \\
\hline$[\$ 100 \mathrm{~m}, \$ 1,000 \mathrm{~m}]$ & 681 & 1,376 & 606 & 2,663 \\
\hline \multirow[t]{2}{*}{$\geq \$ 1,000 \mathrm{~m}$} & 785 & 632 & 134 & 1,551 \\
\hline & 1,696 & 3,222 & 2,474 & 7,392 \\
\hline
\end{tabular}

The total number of firms in the U.S. portfolios based on EDF and asset size categories is 7,392, which is more than the 6,909 U.S. firms reported in Table 2. The difference of 483 firms is due to firms with EDF or asset sizes values that fall at a range's endpoints being included in more than one portfolio.

Table 5B2. Calibrated Average Asset Correlations at the 99.9\% Percentile for the U.S. Portfolios based on EDF and Asset Size Categories

\begin{tabular}{|c|c|c|c|}
\hline \multirow{2}{*}{ Asset size categories } & \multicolumn{3}{|c|}{ EDF categories (\%) } \\
\cline { 2 - 4 } & $\mathbf{( 0 . 0 0 , 0 . 5 2 ]}$ & {$[\mathbf{0 . 5 2}, \mathbf{6 . 9 4}]$} & {$[\mathbf{6 . 9 4 ,}, \mathbf{2 0 . 0 0 ]}$} \\
\hline $\mathbf{( \$ 0 m , \$ 1 0 0 m ]}$ & 0.1375 & 0.1250 & 0.1250 \\
\hline $\mathbf{\$ \$ 1 0 0 m , \$ 1 , 0 0 0 m ]}$ & 0.1875 & 0.1875 & 0.1750 \\
\hline$\geq \$ \mathbf{1 , 0 0 0 m}$ & 0.3250 & 0.2750 & 0.2250 \\
\hline
\end{tabular}

The table reports the average asset correlations for the nine U.S. portfolios calibrated to the $99.9 \%$ percentile of the portfolio value distributions. Unless otherwise noted, the average asset correlations calibrated to the $99.5 \%$ percentile are identical. 
Table 5C1. The Number of Firms in the Japanese Portfolios based on EDF and Asset Size Categories

\begin{tabular}{|c|c|c|c|c|}
\hline \multirow{2}{*}{ Asset size categories } & \multicolumn{3}{|c|}{ EDF categories (\%) } & \\
\cline { 2 - 5 } & $\mathbf{( 0 . 0 0 , 0 . 5 2}]$ & {$[\mathbf{0 . 5 2}, \mathbf{6 . 9 4}]$} & {$[\mathbf{6 . 9 4 ,} \mathbf{2 0 . 0 0 ]}$} & \\
\hline $\mathbf{( \$ 0 m , ~ \$ 2 0 0 m ]}$ & 198 & 843 & 243 & 1,284 \\
\hline [\$200m, \$1,000m] & 251 & 797 & 179 & 1,227 \\
\hline$\geq \$ \mathbf{\$ 1 , 0 0 0 m}$ & 354 & 340 & 64 & 758 \\
\hline & 803 & 1980 & 486 & 3,269 \\
\hline
\end{tabular}

The total number of firms in the Japanese portfolios based on EDF and asset size categories is 3,269, which is more than the 3,255 Japanese firms reported in Table 2. The difference of 14 firms is due to firms with EDF or asset sizes values that fall at a range's endpoints being included in more than one portfolio.

Table 5C2. Calibrated Average Asset Correlations at the 99.9\% Percentile for the Japanese Portfolios based on EDF and Asset Size Categories

\begin{tabular}{|c|c|c|c|}
\hline \multirow{2}{*}{ Asset size categories } & \multicolumn{3}{|c|}{ EDF categories (\%) } \\
\cline { 2 - 4 } & $\mathbf{( 0 . 0 0 , \mathbf { 0 . 5 2 } ]}$ & {$[\mathbf{0 . 5 2}, \mathbf{6 . 9 4}]$} & {$[\mathbf{6 . 9 4 ,}, \mathbf{2 0 . 0 0 ]}$} \\
\hline $\mathbf{( \$ 0 m , \$ 2 0 0 m ]}$ & 0.2250 & 0.2000 & 0.2000 \\
\hline $\mathbf{\$ \$ 2 0 0 m , \$ 1 , 0 0 0 m ]}$ & 0.2500 & 0.2500 & 0.2750 \\
\hline$\geq \$ \mathbf{1 , 0 0 0 m}$ & 0.4250 & 0.4000 & 0.5500 \\
\hline
\end{tabular}

The table reports the average asset correlations for the nine Japanese portfolios calibrated to the $99.9 \%$ percentile of the portfolio value distributions. Unless otherwise noted, the average asset correlations calibrated to the $99.5 \%$ percentile are identical. For the Japanese portfolio consisting of firms with asset sizes of greater than or equal to $\$ 200$ million and less than or equal to $\$ 1,000$ million and EDF values between $0.00 \%$ and $0.52 \%$, the average asset correlation calibrated to the $99.5 \%$ percentile is 0.2250 . For the Japanese portfolio consisting of firms with asset sizes of greater than or equal to $\$ 100$ million and EDF values between $6.94 \%$ and $20.00 \%$, the average asset correlation calibrated to the $99.5 \%$ percentile is 0.4250 , which is lower than the value for the $99.9 \%$ percentile. 
Table 5D1. The Number of Firms in the European Portfolios based on EDF and Asset Size Categories

\begin{tabular}{|c|c|c|c|c|}
\hline \multirow{2}{*}{ Asset size categories } & \multicolumn{3}{|c|}{ EDF categories (\%) } & \multirow{2}{*}{} \\
\cline { 2 - 5 } & $\mathbf{( 0 . 0 0 , 0 . 5 2}]$ & {$[\mathbf{0 . 5 2}, \mathbf{6 . 9 4}]$} & {$[\mathbf{6 . 9 4 , \mathbf { 2 0 . 0 0 } ]}$} & \\
\hline $\mathbf{( \$ 0 m , ~ \$ 2 5 m ]}$ & 207 & 479 & 197 & 883 \\
\hline [\$25m, \$200m] & 519 & 714 & 168 & 1,401 \\
\hline$\geq \mathbf{\$ 2 0 0 m}$ & 887 & 467 & 53 & 1,407 \\
\hline & 1,613 & 1,660 & 418 & 3,691 \\
\hline
\end{tabular}

The total number of firms in the European portfolios based on EDF and asset size categories is 3,691, which is more than the 3,675 European firms reported in Table 2. The difference of 16 firms is due to firms with EDF or asset sizes values that fall at a range's endpoints being included in more than one portfolio.

Table 5D2. Calibrated Average Asset Correlations at the 99.9\% Percentile for the European Portfolios based on EDF and Asset Size Categories

\begin{tabular}{|c|c|c|c|}
\hline \multirow{2}{*}{ Asset size categories } & \multicolumn{3}{|c|}{ EDF categories (\%) } \\
\cline { 2 - 4 } & $\mathbf{( 0 . 0 0 , 0 . 5 2}]$ & {$[\mathbf{0 . 5 2}, \mathbf{6 . 9 4}]$} & {$[\mathbf{6 . 9 4}, \mathbf{2 0 . 0 0 ]}$} \\
\hline $\mathbf{( \$ \mathbf { 0 m } , \mathbf { \$ 2 5 m } ]}$ & 0.1250 & 0.1250 & 0.1250 \\
\hline$[\mathbf{\$ 2 5 m}, \mathbf{\$ 2 0 0 m}]$ & 0.1250 & 0.1250 & 0.1250 \\
\hline$\geq \$ \mathbf{2 0 0 m}$ & 0.2000 & 0.1750 & 0.1750 \\
\hline
\end{tabular}

The table reports the average asset correlations for the nine European portfolios calibrated to the $99.9 \%$ percentile of the portfolio value distributions. Unless otherwise noted, the average asset correlations calibrated to the $99.5 \%$ percentile are identical. 
Table 6. Comparison of Average Asset Correlations for the Aggregate Portfolios

\begin{tabular}{|l|c|c|c|c|c|}
\hline & & & \multicolumn{3}{|c|}{ November Correlation Proposal } \\
\cline { 4 - 6 } Portfolio & $\begin{array}{l}\text { Calibrated } \\
\text { Avg. Asset } \\
\text { Correlation }\end{array}$ & $\begin{array}{l}\text { January } \\
\text { Correlation } \\
\text { Proposal }\end{array}$ & Mean EDF & Med. EDF & Max. EDF \\
\hline All firms & 0.1125 & 0.2000 & 0.1082 & 0.1445 & 0.1000 \\
\hline \hline U.S. firms & 0.1625 & 0.2000 & 0.1033 & 0.1300 & 0.1000 \\
\hline $\begin{array}{l}\text { Japanese } \\
\text { firms }\end{array}$ & 0.2625 & 0.2000 & 0.1176 & 0.1430 & 0.1000 \\
\hline $\begin{array}{l}\text { European } \\
\text { firms }\end{array}$ & 0.1375 & 0.2000 & 0.1238 & 0.1684 & 0.1000 \\
\hline
\end{tabular}

The table contrasts the average asset correlations as calculated in three different ways for the aggregate portfolios. The calibrated average asset correlation is the value reported earlier with respect to the $99.9 \%$ percentile. The January correlation proposal value is the constant value of 0.20 implied in the January 2001 proposal by the Basel Committee on Banking Supervision. The November correlation proposal values are the values derived from the formula in the November 2001 proposal by the Basel Committee on Banking Supervision. The formula is presented in the text. The three PD values examined here are the mean, median and maximum EDF values for the individual portfolios. These values are $[5.0,1.6,20.0]$ for all firms; $[6.8,2.4,20.0]$ for U.S. firms; [3.5, 1.7, 20.0] for Japanese firms; and [2.9, 1.8, 20.0] for European firms. 
Table 7A. Comparison of Average Asset Correlations for the World Portfolios based on EDF Categories

\begin{tabular}{|c|c|c|c|c|c|}
\hline \multirow{2}{*}{$\begin{array}{l}\text { EDF } \\
\text { categories } \\
(\%)\end{array}$} & \multirow{2}{*}{$\begin{array}{l}\text { Calibrated } \\
\text { Avg. Asset } \\
\text { Correlation }\end{array}$} & \multirow{2}{*}{$\begin{array}{l}\text { January } \\
\text { Correlation } \\
\text { Proposal } \\
\end{array}$} & \multicolumn{3}{|c|}{ November Correlation Proposal } \\
\hline & & & Mean EDF & Med. EDF & Max. EDF \\
\hline$(0.00,0.05]$ & 0.1500 & 0.2000 & 0.1986 & 0.1990 & 0.1975 \\
\hline$[0.05,0.52]$ & 0.1500 & 0.2000 & 0.1883 & 0.1891 & 0.1771 \\
\hline$[0.52,2.03]$ & 0.1250 & 0.2000 & 0.1566 & 0.1586 & 0.1362 \\
\hline$[2.03,6.94]$ & 0.1125 & 0.2000 & 0.1144 & 0.1168 & 0.1031 \\
\hline$[6.94,20.00]$ & 0.1000 & 0.2000 & 0.1000 & 0.1000 & 0.1000 \\
\hline
\end{tabular}

The table contrasts the average asset correlations as calculated in three different ways for the world portfolios based on EDF categories. The calibrated average asset correlation is the value reported earlier with respect to the $99.9 \%$ percentile. The January correlation proposal value is the constant value of 0.20 implied in the January 2001 proposal by the Basel Committee on Banking Supervision. The November correlation proposal values are the values derived from the formula in the November 2001 proposal by the Basel Committee on Banking Supervision. The formula is presented in the text. The three PD values examined here are the mean, median and maximum EDF values for the individual portfolios. These values are [0.03, 0.02, 0.05] for the first portfolio; $[0.25,0.23,0.52]$ for the second portfolio; $[1.14,1.07,2.03]$ for the third portfolio; [3.88, 3.57, 6.94] for the fourth portfolio; and [16.02, 20.00, 20.00] for the fifth portfolio.

Table 7B. Comparison of Average Asset Correlations for the U.S. Portfolios based on EDF Categories

\begin{tabular}{|l|c|c|c|c|c|}
\hline & & & \multicolumn{3}{|c|}{ November Correlation Proposal } \\
\cline { 4 - 6 } $\begin{array}{l}\text { EDF } \\
\text { categories } \\
(\%)\end{array}$ & $\begin{array}{l}\text { Calibrated } \\
\text { Avg. Asset } \\
\text { Correlation }\end{array}$ & $\begin{array}{l}\text { January } \\
\text { Correlation } \\
\text { Proposal }\end{array}$ & Mean EDF & Med. EDF & Max. EDF \\
\hline $\mathbf{( 0 . 0 0 , 0 . 0 5 ]}$ & 0.2250 & 0.2000 & 0.1984 & 0.1985 & 0.1975 \\
\hline$[\mathbf{0 . 0 5 , 0 . 5 2}]$ & 0.2500 & 0.2000 & 0.1876 & 0.1882 & 0.1771 \\
\hline$[\mathbf{0 . 5 2 , 2 . 0 3 ]}$ & 0.2000 & 0.2000 & 0.1566 & 0.1583 & 0.1362 \\
\hline$[\mathbf{2 . 0 3 , 6 . 9 4}]$ & 0.1750 & 0.2000 & 0.1140 & 0.1164 & 0.1031 \\
\hline$[\mathbf{6 . 9 4 , 2 0 . 0 0 ]}$ & 0.1500 & 0.2000 & 0.1000 & 0.1000 & 0.1000 \\
\hline
\end{tabular}

The table contrasts the average asset correlations as calculated in three different ways for the U.S. portfolios based on EDF categories. The calibrated average asset correlation is the value reported earlier with respect to the $99.9 \%$ percentile. The January correlation proposal value is the constant value of 0.20 implied in the January 2001 proposal by the Basel Committee on Banking Supervision. The November correlation proposal values are the values derived from the formula in the November 2001 proposal by the Basel Committee on Banking Supervision. The formula is presented in the text. The three PD values examined here are the mean, median and maximum EDF values for the individual portfolios. These values are [0.03, 0.03, 0.05] for the first portfolio; $[0.27,0.25,0.52]$ for the second portfolio; $[1.14,1.08,2.03]$ for the third portfolio; [3.93, 3.61, 6.04] for the fourth portfolio; and [17.0, 20.0, 20.0] for the fifth portfolio. 
Table 7C. Comparison of Average Asset Correlations for the Japanese Portfolios based on EDF Categories

\begin{tabular}{|l|c|l|c|c|c|}
\hline & & & \multicolumn{3}{|c|}{ November Correlation Proposal } \\
\cline { 4 - 6 } $\begin{array}{l}\text { EDF } \\
\text { categories } \\
(\boldsymbol{\%})\end{array}$ & $\begin{array}{l}\text { Calibrated } \\
\text { Avg. Asset } \\
\text { Correlation }\end{array}$ & $\begin{array}{l}\text { January } \\
\text { Correlation } \\
\text { Proposal }\end{array}$ & Mean EDF & Med. EDF & Max. EDF \\
\hline $\mathbf{( 0 . 0 0 , 0 . 0 5 ]}$ & 0.3250 & 0.2000 & 0.1984 & 0.1985 & 0.1975 \\
\hline$[\mathbf{0 . 0 5 , 0 . 5 2}]$ & 0.3250 & 0.2000 & 0.1882 & 0.1887 & 0.1771 \\
\hline$[\mathbf{0 . 5 2 , 2 . 0 3 ]}$ & 0.2750 & 0.2000 & 0.1554 & 0.1566 & 0.1362 \\
\hline$[\mathbf{2 . 0 3 , 6 . 9 4}]$ & 0.2500 & 0.2000 & 0.1144 & 0.1170 & 0.1031 \\
\hline$[\mathbf{6 . 9 4}, \mathbf{2 0 . 0 0}]$ & 0.2750 & 0.2000 & 0.1002 & 0.1003 & 0.1000 \\
\hline
\end{tabular}

The table contrasts the average asset correlations as calculated in three different ways for the Japanese portfolios based on EDF categories. The calibrated average asset correlation is the value reported earlier with respect to the $99.9 \%$ percentile. The January correlation proposal value is the constant value of 0.20 implied in the January 2001 proposal by the Basel Committee on Banking Supervision. The November correlation proposal values are the values derived from the formula in the November 2001 proposal by the Basel Committee on Banking Supervision. The formula is presented in the text. The three PD values examined here are the mean, median and maximum EDF values for the individual portfolios. These values are [0.03, 0.03, 0.05] for the first portfolio; [0.25, 0.24, 0.52] for the second portfolio; $[1.18,1.14,2.03]$ for the third portfolio; $[3.88,3.54,6.94]$ for the fourth portfolio; and $[12.59,11.32,20.00]$ for the fifth portfolio.

Table 7D. Comparison of Average Asset Correlations for the European Portfolios based on EDF Categories

\begin{tabular}{|l|c|c|c|c|c|}
\hline & & & \multicolumn{3}{|c|}{ November Correlation Proposal } \\
\cline { 4 - 6 } $\begin{array}{l}\text { EDF } \\
\text { categories } \\
(\%)\end{array}$ & $\begin{array}{l}\text { Calibrated } \\
\text { Avg. Asset } \\
\text { Correlation }\end{array}$ & $\begin{array}{l}\text { January } \\
\text { Correlation } \\
\text { Proposal }\end{array}$ & Mean EDF & Med. EDF & Max. EDF \\
\hline $\mathbf{( 0 . 0 0 , 0 . 0 5 ]}$ & 0.1750 & 0.2000 & 0.1987 & 0.1990 & 0.1975 \\
\hline$[\mathbf{0 . 0 5 , 0 . 5 2}]$ & 0.1750 & 0.2000 & 0.1891 & 0.1900 & 0.1771 \\
\hline$[\mathbf{0 . 5 2 , 2 . 0 3 ]}$ & 0.1500 & 0.2000 & 0.1577 & 0.1604 & 0.1362 \\
\hline$[\mathbf{2 . 0 3 , 6 . 9 4}]$ & 0.1250 & 0.2000 & 0.1149 & 0.1169 & 0.1031 \\
\hline$[\mathbf{6 . 9 4}, \mathbf{2 0 . 0 0}]$ & 0.1250 & 0.2000 & 0.1001 & 0.1001 & 0.1000 \\
\hline
\end{tabular}

The table contrasts the average asset correlations as calculated in three different ways for the European portfolios based on EDF categories. The calibrated average asset correlation is the value reported earlier with respect to the $99.9 \%$ percentile. The January correlation proposal value is the constant value of 0.20 implied in the January 2001 proposal by the Basel Committee on Banking Supervision. The November correlation proposal values are the values derived from the formula in the November 2001 proposal by the Basel Committee on Banking Supervision. The formula is presented in the text. The three PD values examined here are the mean, median and maximum EDF values for the individual portfolios. These values are [0.03, 0.02, 0.05] for the first portfolio; $[0.23,0.21,0.52]$ for the second portfolio; $[1.10,1.01,2.03]$ for the third portfolio; [3.81, 3.56, 6.93] for the fourth portfolio; and [14.54, 14.80, 20.00] for the fifth portfolio. 
Table 8A. Comparison of Average Asset Correlations

for the World Portfolios based on Asset Size Categories

\begin{tabular}{|c|c|c|c|c|c|}
\hline \multirow{2}{*}{$\begin{array}{l}\text { Asset size } \\
\text { (\$m) }\end{array}$} & \multirow{2}{*}{$\begin{array}{l}\text { Calibrated } \\
\text { Avg. Asset } \\
\text { Correlation }\end{array}$} & \multirow{2}{*}{$\begin{array}{l}\text { January } \\
\text { Correlation } \\
\text { Proposal }\end{array}$} & \multicolumn{3}{|c|}{ November Correlation Proposal } \\
\hline & & & Mean EDF & Med. EDF & Max. EDF \\
\hline$(\$ 0, \$ 20]$ & 0.1000 & 0.2000 & 0.1006 & 0.1012 & 0.1000 \\
\hline$[\$ 20, \$ 100]$ & 0.1000 & 0.2000 & 0.1045 & 0.1250 & 0.1000 \\
\hline$[\$ 100, \$ 300]$ & 0.1125 & 0.2000 & 0.1109 & 0.1423 & 0.1000 \\
\hline [\$300,\$1,000] & 0.1375 & 0.2000 & 0.1190 & 0.1580 & 0.1000 \\
\hline$\geq \$ 1,000$ & 0.2000 & 0.2000 & 0.1389 & 0.1807 & 0.1000 \\
\hline
\end{tabular}

The table contrasts the average asset correlations as calculated in three different ways for the world portfolios based on asset size categories. The calibrated average asset correlation is the value reported earlier with respect to the $99.9 \%$ percentile. The January correlation proposal value is the constant value of 0.20 implied in the January 2001 proposal by the Basel Committee on Banking Supervision. The November correlation proposal values are the values derived from the formula in the November 2001 proposal by the Basel Committee on Banking Supervision. The formula is presented in the text. The three PD values examined here are the mean, median and maximum EDF values for the individual portfolios. These values are $[10.37,8.92,20.00]$ for the first portfolio; $[6.19,2.77,20.00]$ for the second portfolio; $[4.43,1.72,20.00]$ for the third portfolio; $[3.32,1.08,20.00]$ for the fourth portfolio; and $[1.89,0.43,20.00]$ for the fifth portfolio.

Table 8B. Comparison of Average Asset Correlations for the U.S. Portfolios based on Asset Size Categories

\begin{tabular}{|l|c|c|c|c|c|}
\hline & & & \multicolumn{3}{|c|}{ November Correlation Proposal } \\
\cline { 4 - 6 } $\begin{array}{l}\text { Asset size } \\
\mathbf{( \$ m})\end{array}$ & $\begin{array}{l}\text { Calibrated } \\
\text { Avg. Asset } \\
\text { Correlation }\end{array}$ & $\begin{array}{l}\text { January } \\
\text { Correlation } \\
\text { Proposal }\end{array}$ & Mean EDF & Med. EDF & Max. EDF \\
\cline { 4 - 6 } & 0.1000 & 0.2000 & 0.1002 & 0.1000 & 0.1000 \\
\hline $\mathbf{( 0 . 0 0 , 0 . 0 5 ]}$ & 0.1500 & 0.2000 & 0.1013 & 0.1071 & 0.1000 \\
\hline$[\mathbf{0 . 0 5 , 0 . 5 2}]$ & 0.1750 & 0.2000 & 0.1052 & 0.1351 & 0.1000 \\
\hline$[\mathbf{0 . 5 2}, \mathbf{2 . 0 3}]$ & 0.2250 & 0.2000 & 0.1132 & 0.1577 & 0.1000 \\
\hline$[\mathbf{2 . 0 3}, \mathbf{6 . 9 4}]$ & 0.3000 & 0.2000 & 0.1321 & 0.1779 & 0.1000 \\
\hline$[\mathbf{6 . 9 4}, \mathbf{2 0 . 0 0}]$ & & & & &
\end{tabular}

The table contrasts the average asset correlations as calculated in three different ways for the U.S. portfolios based on asset size categories. The calibrated average asset correlation is the value reported earlier with respect to the $99.9 \%$ percentile. The January correlation proposal value is the constant value of 0.20 implied in the January 2001 proposal by the Basel Committee on Banking Supervision. The November correlation proposal values are the values derived from the formula in the November 2001 proposal by the Basel Committee on Banking Supervision. The formula is presented in the text. The three PD values examined here are the mean, median and maximum EDF values for the individual portfolios. These values are [12.6, 15.6, 20.00] for the first portfolio; [8.6, 5.3, 20.00] for the second portfolio; $[5.9,2.1,20.00]$ for the third portfolio; $[4.0,1.1,20.00]$ for the fourth portfolio; and $[2.3,0.5,20.00]$ for the fifth portfolio. 
Table 8C. Comparison of Average Asset Correlations for the Japanese Portfolios based on Asset Size Categories

\begin{tabular}{|c|c|c|c|c|c|}
\hline \multirow{2}{*}{$\begin{array}{l}\text { Asset size } \\
\text { (\$m) }\end{array}$} & \multirow{2}{*}{$\begin{array}{l}\text { Calibrated } \\
\text { Avg. Asset } \\
\text { Correlation }\end{array}$} & \multirow{2}{*}{$\begin{array}{l}\text { January } \\
\text { Correlation } \\
\text { Proposal } \\
\end{array}$} & \multicolumn{3}{|c|}{ November Correlation Proposal } \\
\hline & & & Mean EDF & Med. EDF & Max. EDF \\
\hline$(\$ 0, \$ 100]$ & 0.2000 & 0.2000 & 0.1115 & 0.1268 & 0.1000 \\
\hline$[\$ 100, \$ 200]$ & 0.2000 & 0.2000 & 0.1128 & 0.1307 & 0.1000 \\
\hline$[\$ 200, \$ 400]$ & 0.2500 & 0.2000 & 0.1155 & 0.1370 & 0.1000 \\
\hline$[\$ 400, \$ 1,000]$ & 0.3000 & 0.2000 & 0.1189 & 0.1417 & 0.1000 \\
\hline$\geq \$ 1,000$ & 0.4500 & 0.2000 & 0.1350 & 0.1733 & 0.1000 \\
\hline
\end{tabular}

The table contrasts the average asset correlations as calculated in three different ways for the world portfolios based on asset size categories. The calibrated average asset correlation is the value reported earlier with respect to the $99.9 \%$ percentile. The January correlation proposal value is the constant value of 0.20 implied in the January 2001 proposal by the Basel Committee on Banking Supervision. The November correlation proposal values are the values derived from the formula in the November 2001 proposal by the Basel Committee on Banking Supervision. The formula is presented in the text. The three PD values examined here are the mean, median and maximum EDF values for the individual portfolios. These values are $[4.3,2.6,20.0]$ for the first portfolio; $[4.1,2.4,20.0]$ for the second portfolio; $[3.7,2.0,20.0]$ for the third portfolio; $[3.3,1.8,20.0]$ for the fourth portfolio; and $[2.1,0.6,20.0]$ for the fifth portfolio.

Table 8D. Comparison of Average Asset Correlations for the European Portfolios based on Asset Size Categories

\begin{tabular}{|c|c|c|c|c|c|}
\hline \multirow{2}{*}{$\begin{array}{l}\text { Asset size } \\
(\$ \mathrm{~m})\end{array}$} & \multirow{2}{*}{$\begin{array}{l}\text { Calibrated } \\
\text { Avg. Asset } \\
\text { Correlation }\end{array}$} & \multirow{2}{*}{$\begin{array}{l}\text { January } \\
\text { Correlation } \\
\text { Proposal }\end{array}$} & \multicolumn{3}{|c|}{ November Correlation Proposal } \\
\hline & & & Mean EDF & Med. EDF & Max. EDF \\
\hline$(\$ 0, \$ 25]$ & 0.1250 & 0.2000 & 0.1080 & 0.1288 & 0.1000 \\
\hline$[\$ 25, \$ 75]$ & 0.1000 & 0.2000 & 0.1162 & 0.1537 & 0.1000 \\
\hline$[\$ 75, \$ 200]$ & 0.1250 & 0.2000 & 0.1294 & 0.1684 & 0.1000 \\
\hline$[\$ 200, \$ 1,000]$ & 0.1500 & 0.2000 & 0.1430 & 0.1807 & 0.1000 \\
\hline$\geq \$ 1,000$ & 0.2250 & 0.2000 & 0.1672 & 0.1896 & 0.1000 \\
\hline
\end{tabular}

The table contrasts the average asset correlations as calculated in three different ways for the European portfolios based on asset size categories. The calibrated average asset correlation is the value reported earlier with respect to the $99.9 \%$ percentile. The January correlation proposal value is the constant value of 0.20 implied in the January 2001 proposal by the Basel Committee on Banking Supervision. The November correlation proposal values are the values derived from the formula in the November 2001 proposal by the Basel Committee on Banking Supervision. The formula is presented in the text. The three PD values examined here are the mean, median and maximum EDF values for the individual portfolios. These values are $[5.0,2.5,20.0]$ for the first portfolio; $[3.6,1.2,20.0]$ for the second portfolio; $[2.4,0.8,20.0]$ for the third portfolio; $[1.7,0.4,20.0]$ for the fourth portfolio; and $[0.8,0.2,20.0]$ for the fifth portfolio. 
Table 9A. Comparison of Average Asset Correlations for the World Portfolios based on EDF and Asset Size Categories

\begin{tabular}{|c|c|c|c|c|c|c|}
\hline \multicolumn{2}{|c|}{$\begin{array}{l}\text { [Asset size, EDF] } \\
\text { categories }\end{array}$} & \multirow{2}{*}{$\begin{array}{l}\text { Calib. } \\
\text { Avg. Asset } \\
\text { Corr. }\end{array}$} & \multirow{2}{*}{$\begin{array}{l}\text { January } \\
\text { Corr. } \\
\text { Proposal }\end{array}$} & \multicolumn{3}{|c|}{ November Correlation Proposal } \\
\hline $\begin{array}{l}\text { Asset size } \\
(\$ \mathrm{~m})\end{array}$ & $\operatorname{EDF}(\%)$ & & & Mean EDF & Med. EDF & Max. EDF \\
\hline \multirow{3}{*}{$(0,75]$} & $(0.00,0.52]$ & 0.1000 & 0.2000 & 0.1895 & 0.1909 & 0.1771 \\
\hline & {$[0.52,6.94]$} & 0.1000 & 0.2000 & 0.1250 & 0.1311 & 0.1031 \\
\hline & {$[6.94,20.00]$} & 0.1000 & 0.2000 & 0.1000 & 0.1000 & 0.1000 \\
\hline \multirow{3}{*}[75,500]{} & $(0.00,0.52]$ & 0.1125 & 0.2000 & 0.1895 & 0.1905 & 0.1771 \\
\hline & {$[0.52,6.94]$} & 0.1125 & 0.2000 & 0.1300 & 0.1395 & 0.1031 \\
\hline & {$[6.94,20.00]$} & 0.1125 & 0.2000 & 0.1001 & 0.1000 & 0.1000 \\
\hline \multirow{3}{*}{$\geq \mathbf{5 0 0}$} & $(0.00,0.52]$ & 0.2000 & 0.2000 & 0.1898 & 0.1909 & 0.1771 \\
\hline & {$[0.52,6.94]$} & 0.1750 & 0.2000 & 0.1392 & 0.1504 & 0.1031 \\
\hline & {$[6.94,20.00]$} & 0.1625 & 0.2000 & 0.1000 & 0.1000 & 0.1000 \\
\hline
\end{tabular}

The table contrasts the average asset correlations as calculated in three different ways for the world portfolios based on asset size and EDF categories. The calibrated average asset correlation is the value reported earlier with respect to the $99.9 \%$ percentile. The January correlation proposal value is the constant value of 0.20 implied in the January 2001 proposal by the Basel Committee on Banking Supervision. The November correlation proposal values are the values derived from the formula in the November 2001 proposal by the Basel Committee on Banking Supervision. The formula is presented in the text. The three PD values examined here are the mean, median and maximum EDF values for the individual portfolios. These values are $[0.22,0.19,0.52]$ for the first portfolio; $[2.77,2.34,6.94]$ for the second portfolio; [16.55, 20.00, 20.00] for the third portfolio; [0.22, 0.20, 0.52] for the fourth portfolio; $[2.41,1.86,6.94]$ for the fifth portfolio; $[15.14,16.64,20.00]$ for the sixth portfolio;. [0.21, 0.19, 0.52] for the seventh portfolio; [1.87, 1.37, 6.92] for the eighth portfolio; and [15.55, 18.61, 20.00] for the ninth portfolio. 
Table 9B. Comparison of Average Asset Correlations for the U.S. Portfolios based on EDF and Asset Size Categories

\begin{tabular}{|c|c|c|c|c|c|c|}
\hline \multicolumn{2}{|c|}{$\begin{array}{l}\text { [Asset size, EDF] } \\
\text { categories }\end{array}$} & \multirow{2}{*}{$\begin{array}{l}\text { Calib. } \\
\text { Avg. Asset } \\
\text { Corr. }\end{array}$} & \multirow{2}{*}{$\begin{array}{l}\text { January } \\
\text { Corr. } \\
\text { Proposal }\end{array}$} & \multicolumn{3}{|c|}{ November Correlation Proposal } \\
\hline $\begin{array}{l}\text { Asset size } \\
\text { (\$m) }\end{array}$ & $\operatorname{EDF}(\%)$ & & & Mean EDF & Med. EDF & Max. EDF \\
\hline \multirow{3}{*}{$(0,100]$} & $(0.00,0.52]$ & 0.1375 & 0.2000 & 0.1882 & 0.1887 & 0.1771 \\
\hline & {$[0.52,6.94]$} & 0.1250 & 0.2000 & 0.1231 & 0.1277 & 0.1031 \\
\hline & {$[6.94,20.00]$} & 0.1250 & 0.2000 & 0.1000 & 0.1000 & 0.1000 \\
\hline \multirow{3}{*}[100,1,000]{} & $(0.00,0.52]$ & 0.1875 & 0.2000 & 0.1876 & 0.1882 & 0.1771 \\
\hline & {$[0.52,6.94]$} & 0.1875 & 0.2000 & 0.1334 & 0.1453 & 0.1031 \\
\hline & {$[6.94,20.00]$} & 0.1750 & 0.2000 & 0.1000 & 0.1000 & 0.1000 \\
\hline \multirow{3}{*}{$\geq 1,000$} & $(0.00,0.52]$ & 0.3250 & 0.2000 & 0.1891 & 0.1900 & 0.1771 \\
\hline & {$[0.52,6.94]$} & 0.2750 & 0.2000 & 0.1422 & 0.1534 & 0.1031 \\
\hline & {$[6.94,20.00]$} & 0.2250 & 0.2000 & 0.1000 & 0.1000 & 0.1000 \\
\hline
\end{tabular}

The table contrasts the average asset correlations as calculated in three different ways for the U.S. portfolios based on asset size and EDF categories. The calibrated average asset correlation is the value reported earlier with respect to the $99.9 \%$ percentile. The January correlation proposal value is the constant value of 0.20 implied in the January 2001 proposal by the Basel Committee on Banking Supervision. The November correlation proposal values are the values derived from the formula in the November 2001 proposal by the Basel Committee on Banking Supervision. The formula is presented in the text. The three PD values examined here are the mean, median and maximum EDF values for the individual portfolios. These values are $[0.25,0.24,0.52]$ for the first portfolio; $[2.93,2.57,6.94]$ for the second portfolio; $[17.17,20.0$, $20.00]$ for the third portfolio; $[0.26,0.25,0.52]$ for the fourth portfolio; $[2.20,1.59,6.94]$ for the fifth portfolio; $[16.58,20.00,20.00]$ for the sixth portfolio;. [0.23, 0.21, 0.52] for the seventh portfolio; [1.72, 1.26, 6.92] for the eighth portfolio; and [16.70, 20.00, 20.00] for the ninth portfolio. 
Table 9C. Comparison of Average Asset Correlations for the Japanese Portfolios based on EDF and Asset Size Categories

\begin{tabular}{|c|c|c|c|c|c|c|}
\hline \multicolumn{2}{|c|}{$\begin{array}{l}\text { [Asset size, EDF] } \\
\text { categories }\end{array}$} & \multirow{2}{*}{$\begin{array}{l}\text { Calib. } \\
\text { Avg. Asset } \\
\text { Corr. }\end{array}$} & \multirow{2}{*}{$\begin{array}{l}\text { January } \\
\text { Corr. } \\
\text { Proposal }\end{array}$} & \multicolumn{3}{|c|}{ November Correlation Proposal } \\
\hline $\begin{array}{l}\text { Asset size } \\
(\$ \mathrm{~m})\end{array}$ & $\operatorname{EDF}(\%)$ & & & Mean EDF & Med. EDF & Max. EDF \\
\hline \multirow{3}{*}{$(0,200]$} & $(0.00,0.52]$ & 0.2250 & 0.2000 & 0.1879 & 0.1878 & 0.1771 \\
\hline & {$[0.52,6.94]$} & 0.2000 & 0.2000 & 0.1255 & 0.1317 & 0.1031 \\
\hline & {$[6.94,20.00]$} & 0.2000 & 0.2000 & 0.1002 & 0.1003 & 0.1000 \\
\hline \multirow{3}{*}[200,1,000]{} & $(0.00,0.52]$ & 0.2250 & 0.2000 & 0.1892 & 0.1905 & 0.1771 \\
\hline & {$[0.52,6.94]$} & 0.2500 & 0.2000 & 0.1282 & 0.1370 & 0.1032 \\
\hline & {$[6.94,20.00]$} & 0.2750 & 0.2000 & 0.1002 & 0.1005 & 0.1000 \\
\hline \multirow{3}{*}{$\geq \mathbf{1 , 0 0 0}$} & $(0.00,0.52]$ & 0.4250 & 0.2000 & 0.1894 & 0.1903 & 0.1771 \\
\hline & {$[0.52,6.94]$} & 0.4000 & 0.2000 & 0.1379 & 0.1477 & 0.1037 \\
\hline & {$[6.94,20.00]$} & 0.5500 & 0.2000 & 0.1001 & 0.1002 & 0.1000 \\
\hline
\end{tabular}

The table contrasts the average asset correlations as calculated in three different ways for the European portfolios based on asset size and EDF categories. The calibrated average asset correlation is the value reported earlier with respect to the $99.9 \%$ percentile. The January correlation proposal value is the constant value of 0.20 implied in the January 2001 proposal by the Basel Committee on Banking Supervision. The November correlation proposal values are the values derived from the formula in the November 2001 proposal by the Basel Committee on Banking Supervision. The formula is presented in the text. The three PD values examined here are the mean, median and maximum EDF values for the individual portfolios. These values are $[0.257,0.260,0.520]$ for the first portfolio; $[2.735,2.300,6.940]$ for the second portfolio; $[12.409,11.450,20.000]$ for the third portfolio; $[0.228,0.200,0.520]$ for the fourth portfolio; $[2.529,1.990,6.860]$ for the fifth portfolio; $[12.566,10.800,20.000]$ for the sixth portfolio;. [0.224, 0.205, 0.520] for the seventh portfolio; $[1.940,1.480,6.610]$ for the eighth portfolio; and $[13.326,12.420,20.000]$ for the ninth portfolio. 
Table 9D. Comparison of Average Asset Correlations for the European Portfolios based on EDF and Asset Size Categories

\begin{tabular}{|c|c|c|c|c|c|c|}
\hline \multicolumn{2}{|c|}{$\begin{array}{l}\text { [Asset size, EDF] } \\
\text { categories }\end{array}$} & \multirow{2}{*}{$\begin{array}{l}\text { Calib. } \\
\text { Avg. Asset } \\
\text { Corr. }\end{array}$} & \multirow{2}{*}{$\begin{array}{l}\text { January } \\
\text { Corr. } \\
\text { Proposal }\end{array}$} & \multicolumn{3}{|c|}{ November Correlation Proposal } \\
\hline $\begin{array}{l}\text { Asset size } \\
(\$ \mathbf{m})\end{array}$ & $\operatorname{EDF}(\%)$ & & & Mean EDF & Med. EDF & Max. EDF \\
\hline \multirow{3}{*}{$(0,25]$} & $(0.00,0.52]$ & 0.1250 & 0.2000 & 0.1895 & 0.1909 & 0.1771 \\
\hline & {$[0.52,6.94]$} & 0.1250 & 0.2000 & 0.1253 & 0.1310 & 0.1031 \\
\hline & {$[6.94,20.00]$} & 0.1250 & 0.2000 & 0.1001 & 0.1001 & 0.1000 \\
\hline \multirow{3}{*}[25,200]{} & $(0.00,0.52]$ & 0.1250 & 0.2000 & 0.1912 & 0.1932 & 0.1771 \\
\hline & {$[0.52,6.94]$} & 0.1250 & 0.2000 & 0.1339 & 0.1438 & 0.1053 \\
\hline & {$[6.94,20.00]$} & 0.1250 & 0.2000 & 0.1001 & 0.1001 & 0.1000 \\
\hline \multirow{3}{*}{$\geq 200$} & $(0.00,0.52]$ & 0.2000 & 0.2000 & 0.1919 & 0.1937 & 0.1771 \\
\hline & {$[0.52,6.94]$} & 0.1750 & 0.2000 & 0.1422 & 0.1554 & 0.1032 \\
\hline & {$[6.94,20.00]$} & 0.1750 & 0.2000 & 0.1001 & 0.1001 & 0.1000 \\
\hline
\end{tabular}

The table contrasts the average asset correlations as calculated in three different ways for the Japanese portfolios based on asset size and EDF categories. The calibrated average asset correlation is the value reported earlier with respect to the $99.9 \%$ percentile. The January correlation proposal value is the constant value of 0.20 implied in the January 2001 proposal by the Basel Committee on Banking Supervision. The November correlation proposal values are the values derived from the formula in the November 2001 proposal by the Basel Committee on Banking Supervision. The formula is presented in the text. The three PD values examined here are the mean, median and maximum EDF values for the individual portfolios. These values are $[0.222,0.190,0.520]$ for the first portfolio; $[2.748,2.340,6.930]$ for the second portfolio; $[14.649,15.040,20.000]$ for the third portfolio; $[0.185,0.140,0.520]$ for the fourth portfolio; $[2.162,1.650,6.700]$ for the fifth portfolio; $[14.450,14.250,20.000]$ for the sixth portfolio;. $[0.170,0.130,0.520]$ for the seventh portfolio; $[1.727,1.180,6.900]$ for the eighth portfolio; and $[14.405,15.03,20.000]$ for the ninth portfolio. 
Figure 1.

Calibrated Average Asset Correlations for the Aggregate Portfolios

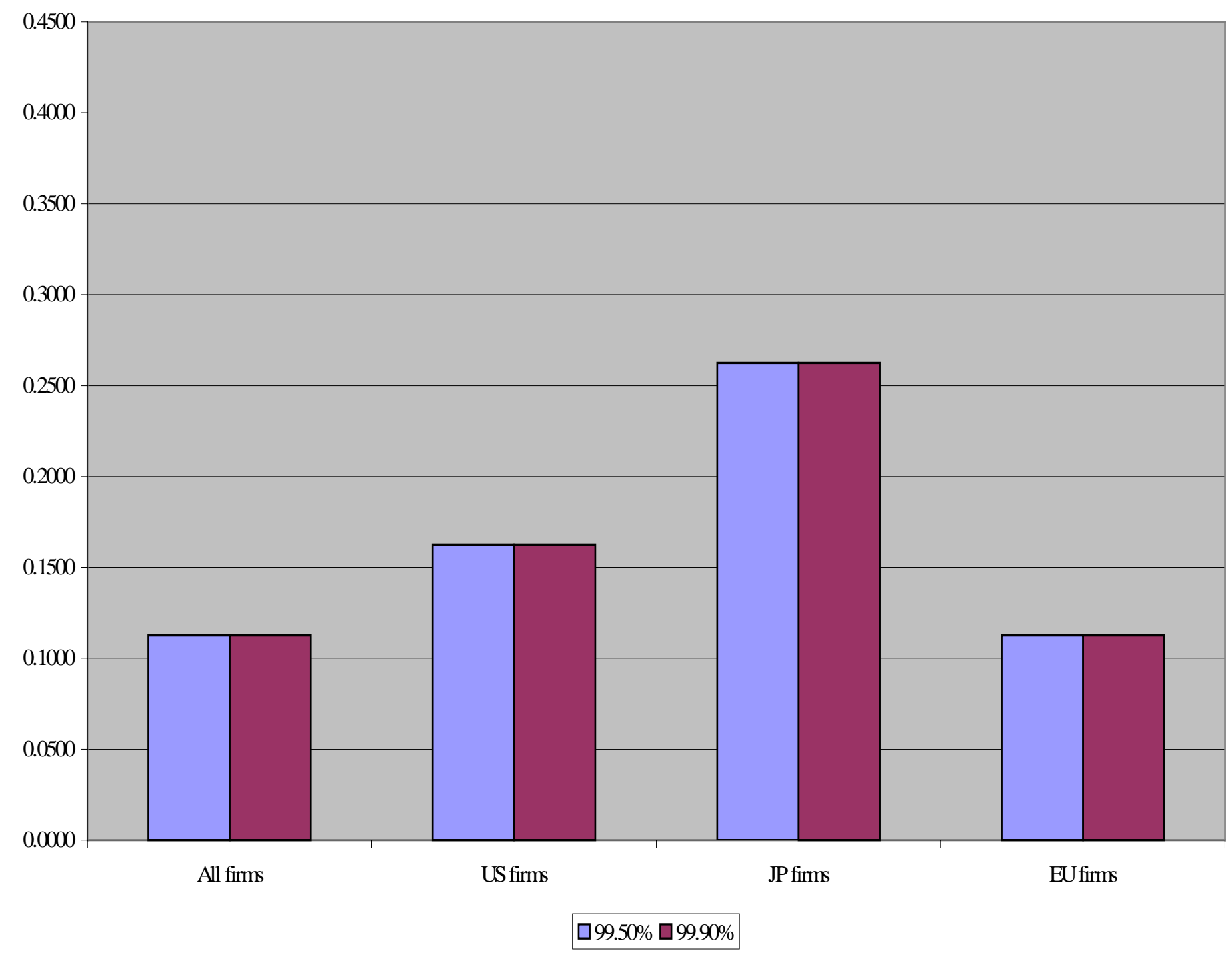


Figure 2A.

Calibrated Average Asset Correlations for World Portfolios based on EDF Categories

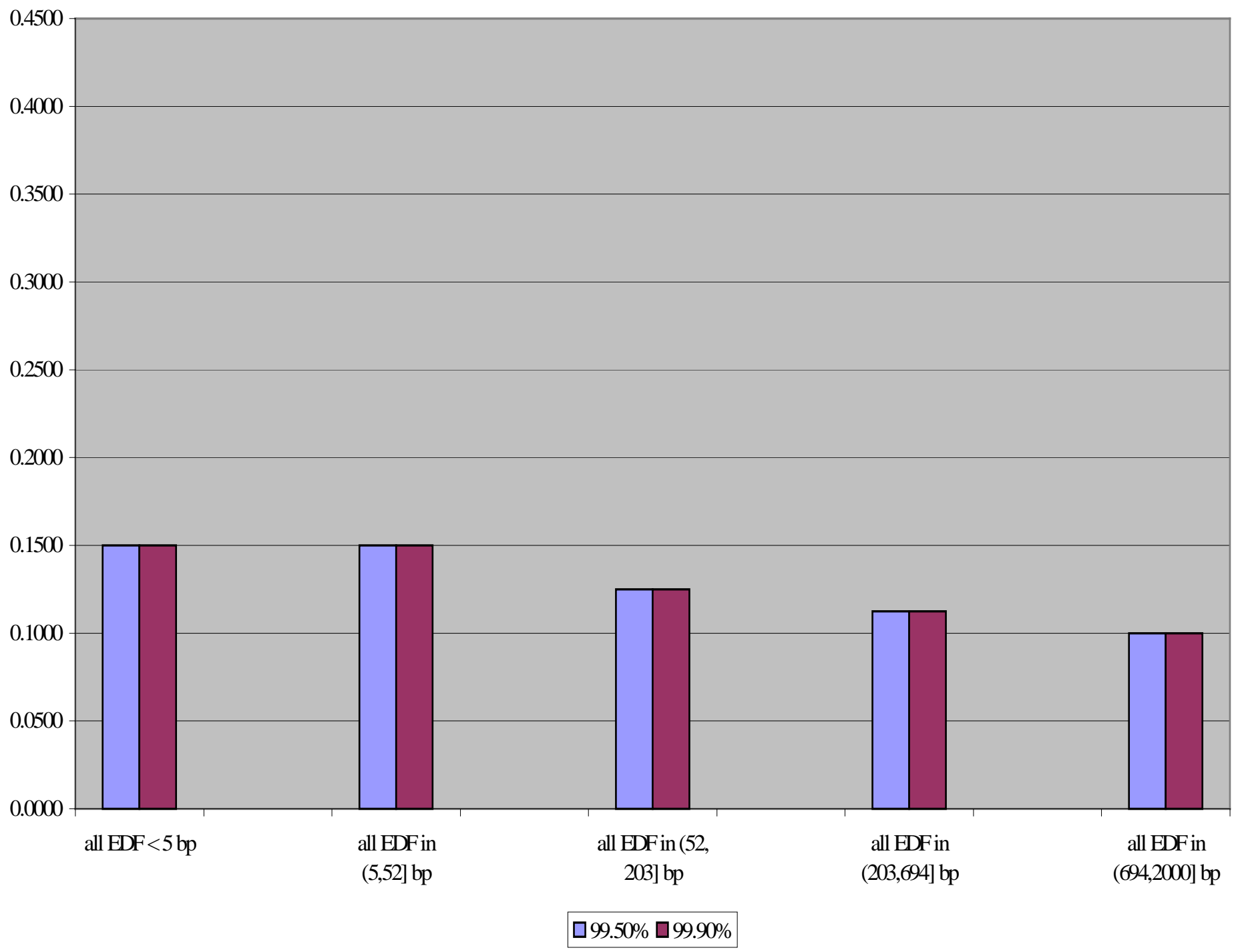


Figure 2B.

\section{Calibrated Average Asset Correlation for U.S. Portfolios based on EDF Categories}

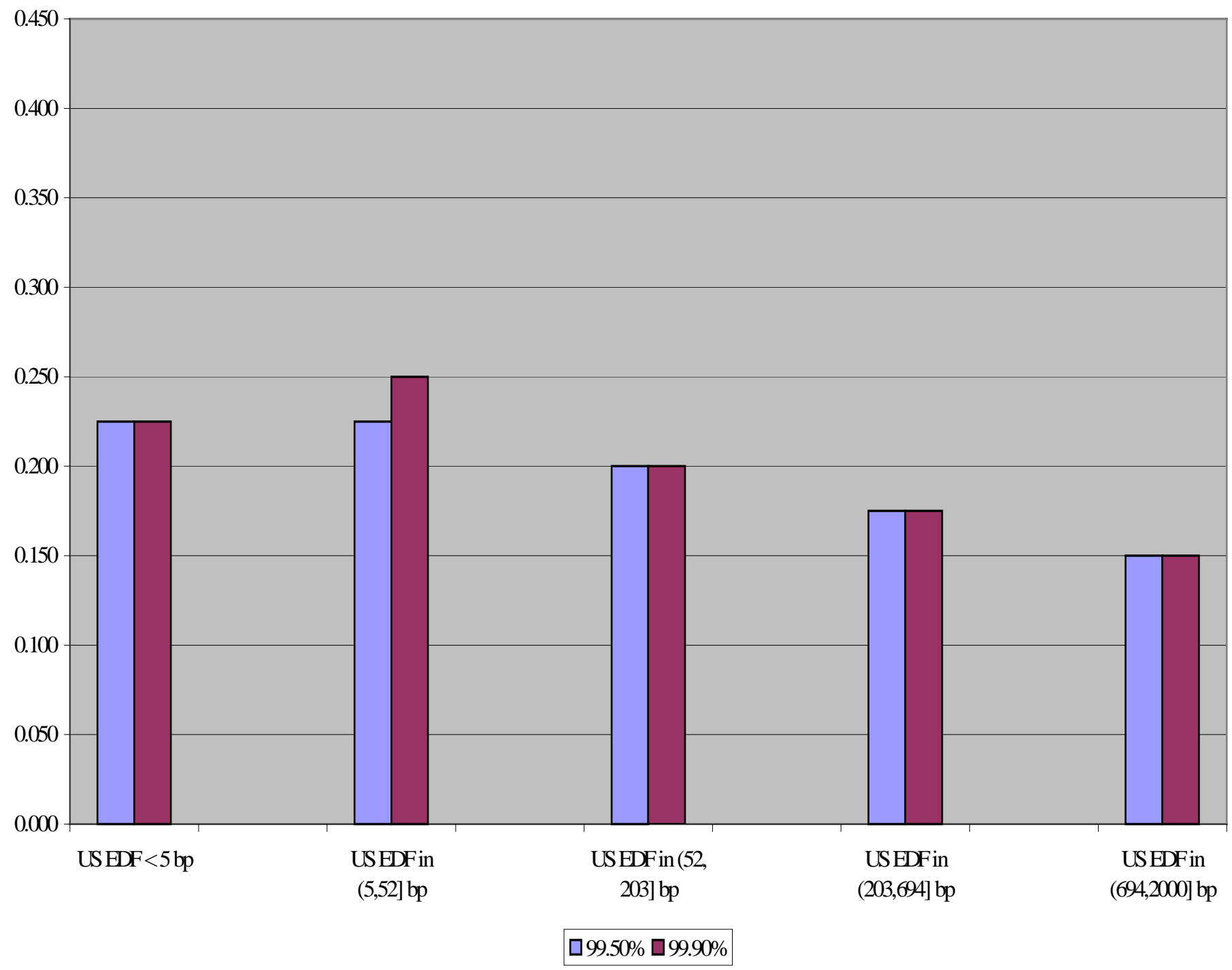


Figure 2C.

Calibrated Average Asset Correlation for Japanese Portfolios Based on EDF Categories

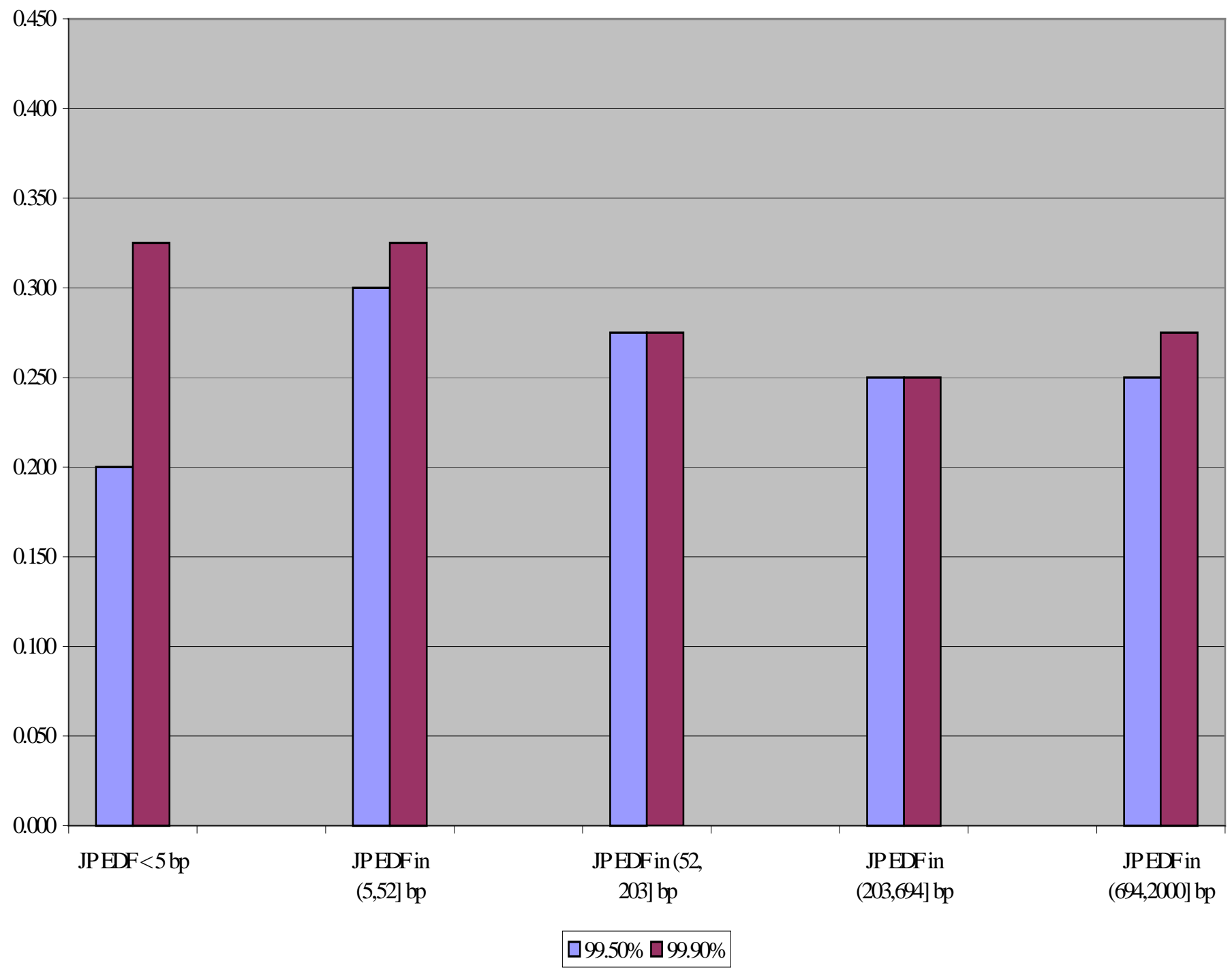


Figure 2D.

Calibrated Average Asset Correlation for European Portfolios Based on EDF Categories

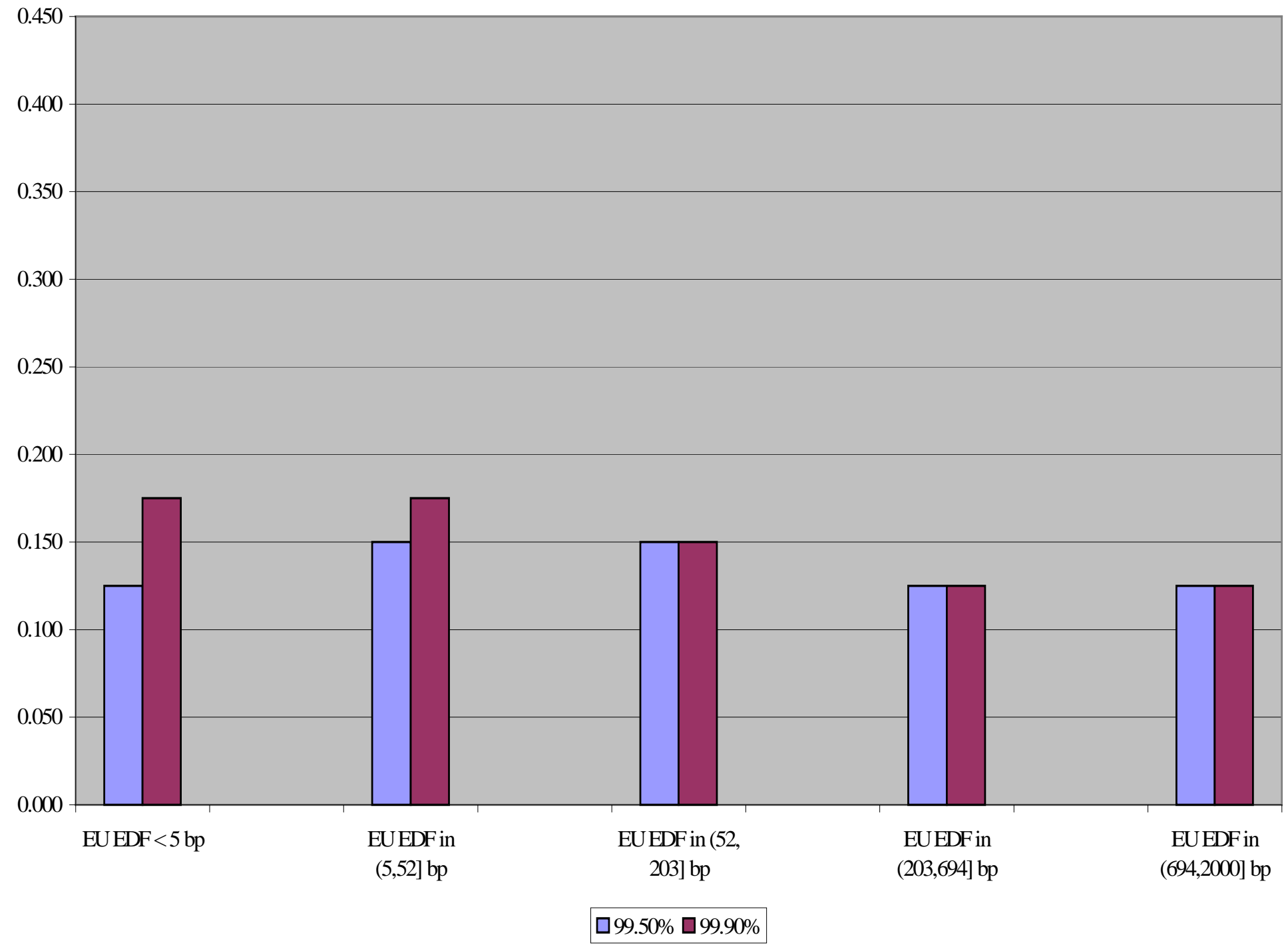


Figure 3A.

Calibrated Average Asset Correlations for World Portfolios based on Asset Size Categories

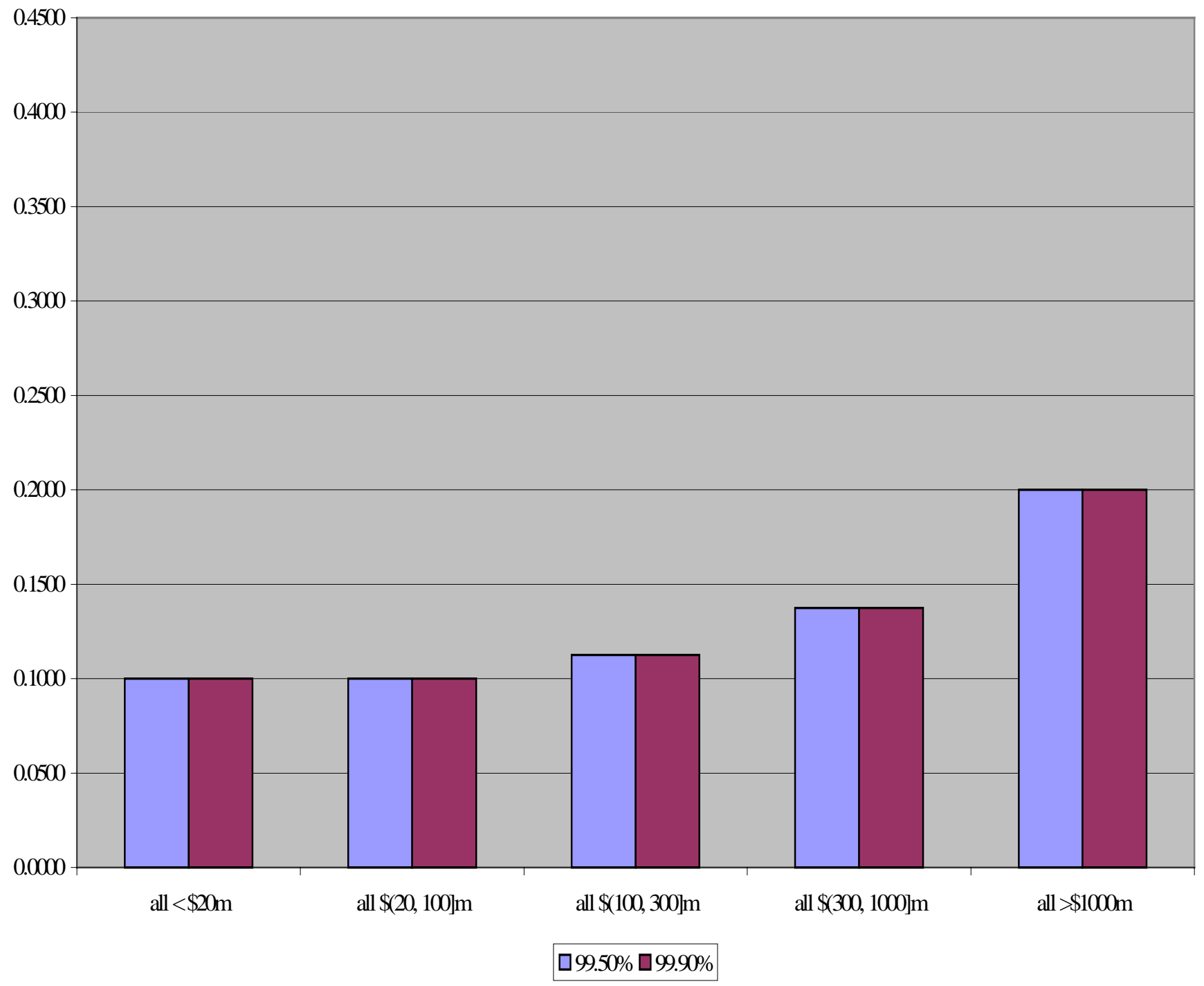


Figure 3B.

Calibrated Average Asset Correlation for U.S. Portfolios Based on Asset Size Categories

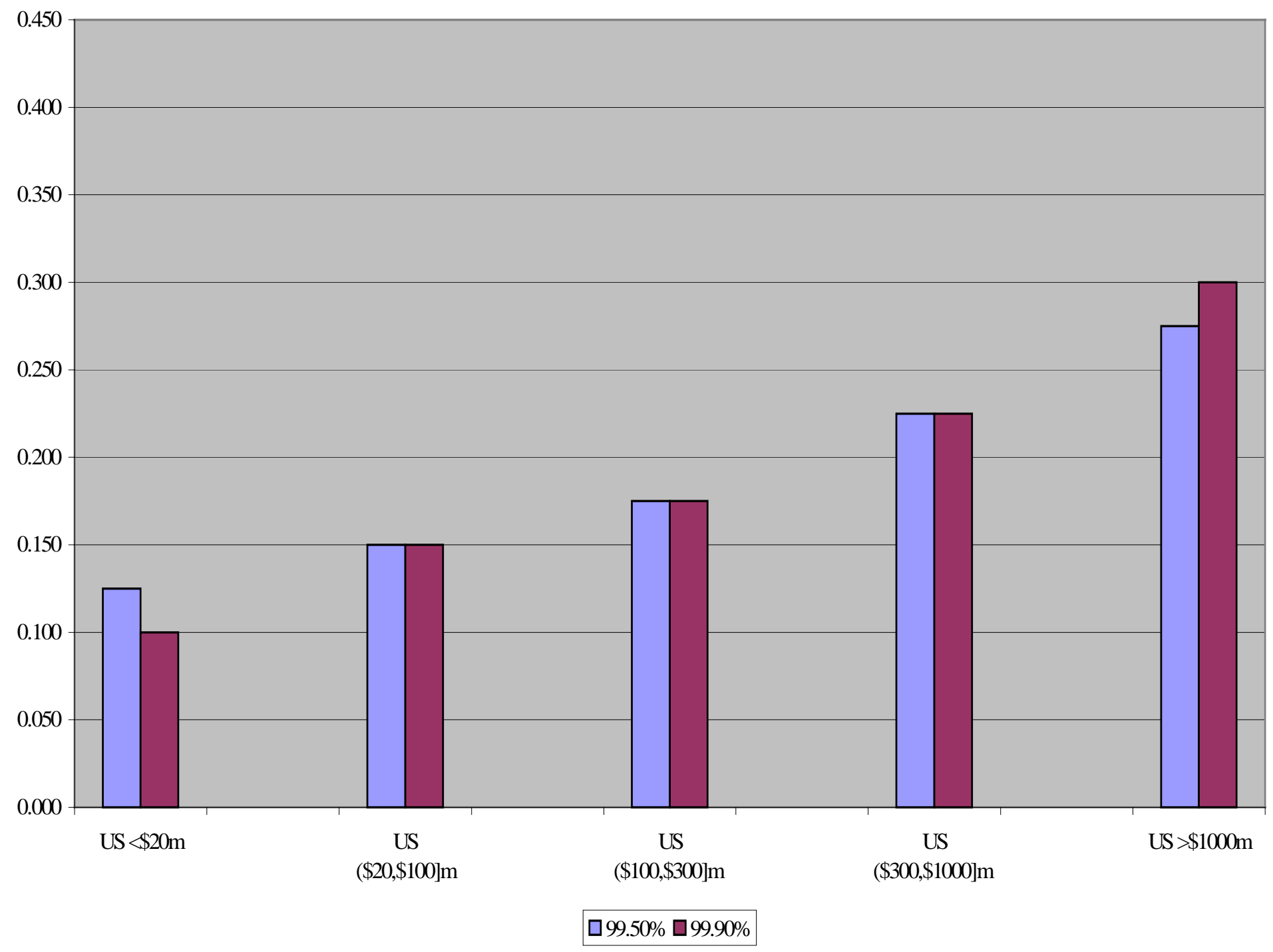


Figure 3C.

Calibrated Average Asset Correlations for Japanese Portfolios based on Asset Size Categories

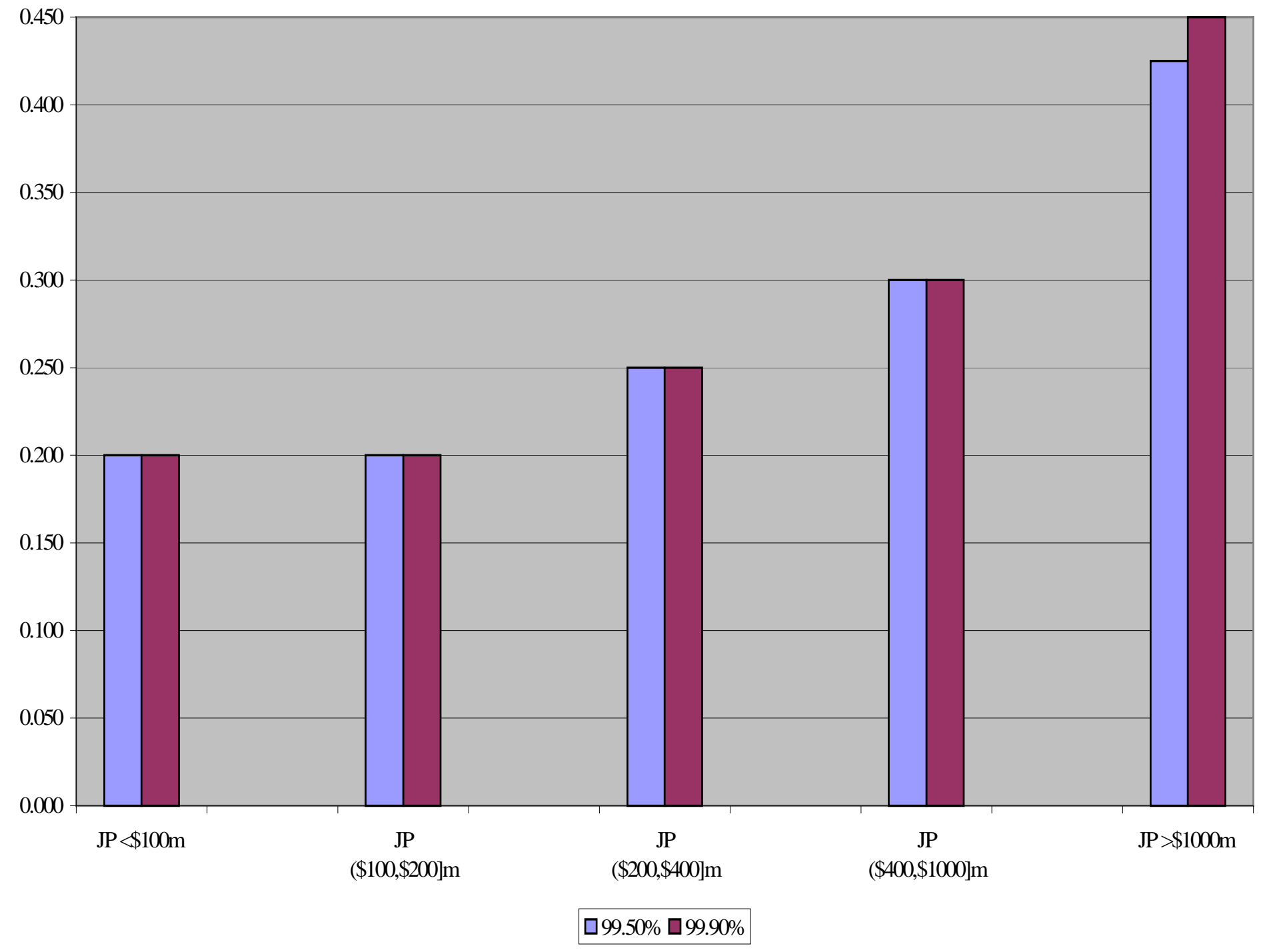


Figure 3D.

Calibrated Average Asset Correlations for European Portfolios based on Asset Size Categories

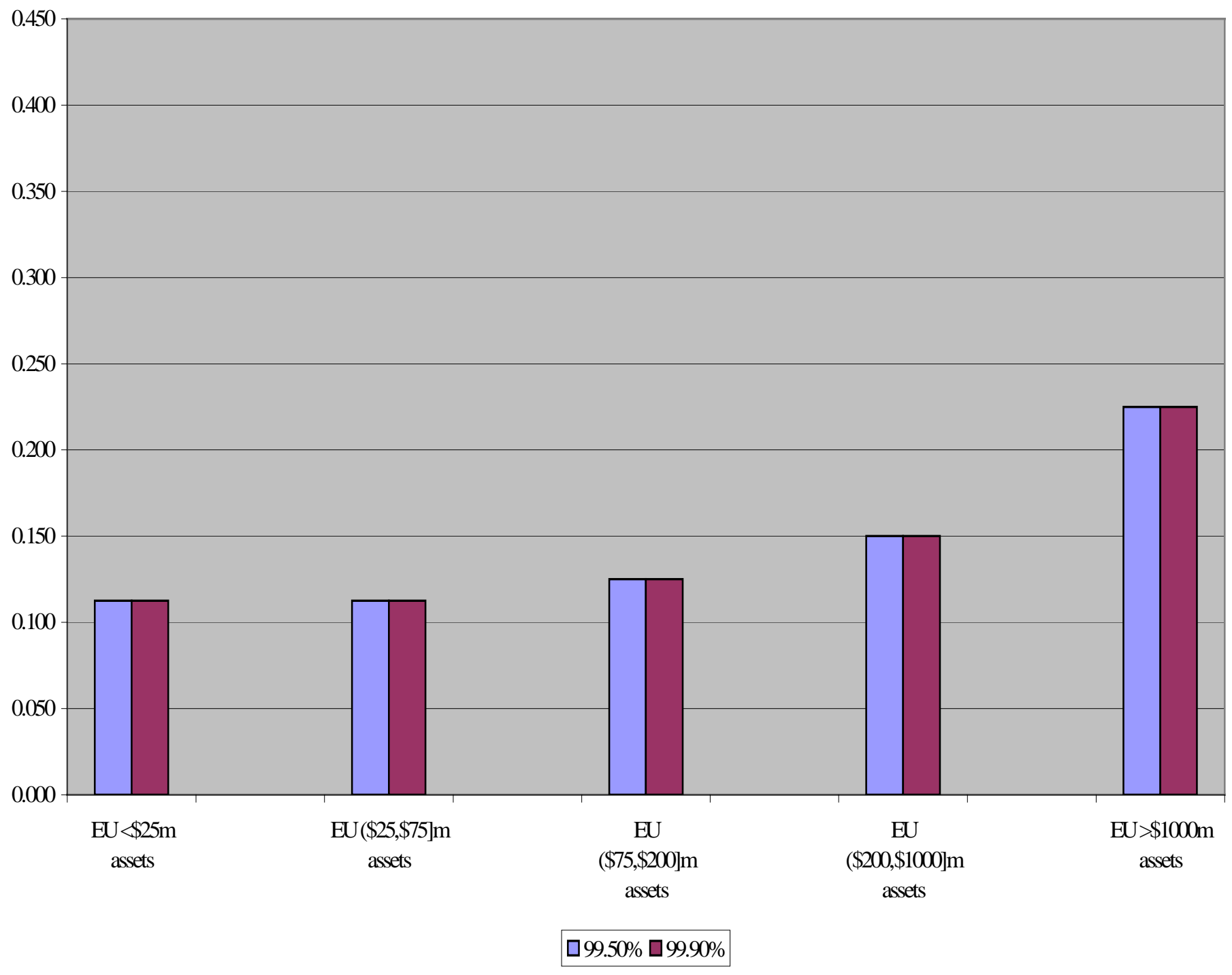


Figure 4A.

Calibrated Average Asset Correlations at the 99.9\% Percentile for World Portfolios based on FirmEDF and Asset Size Categories

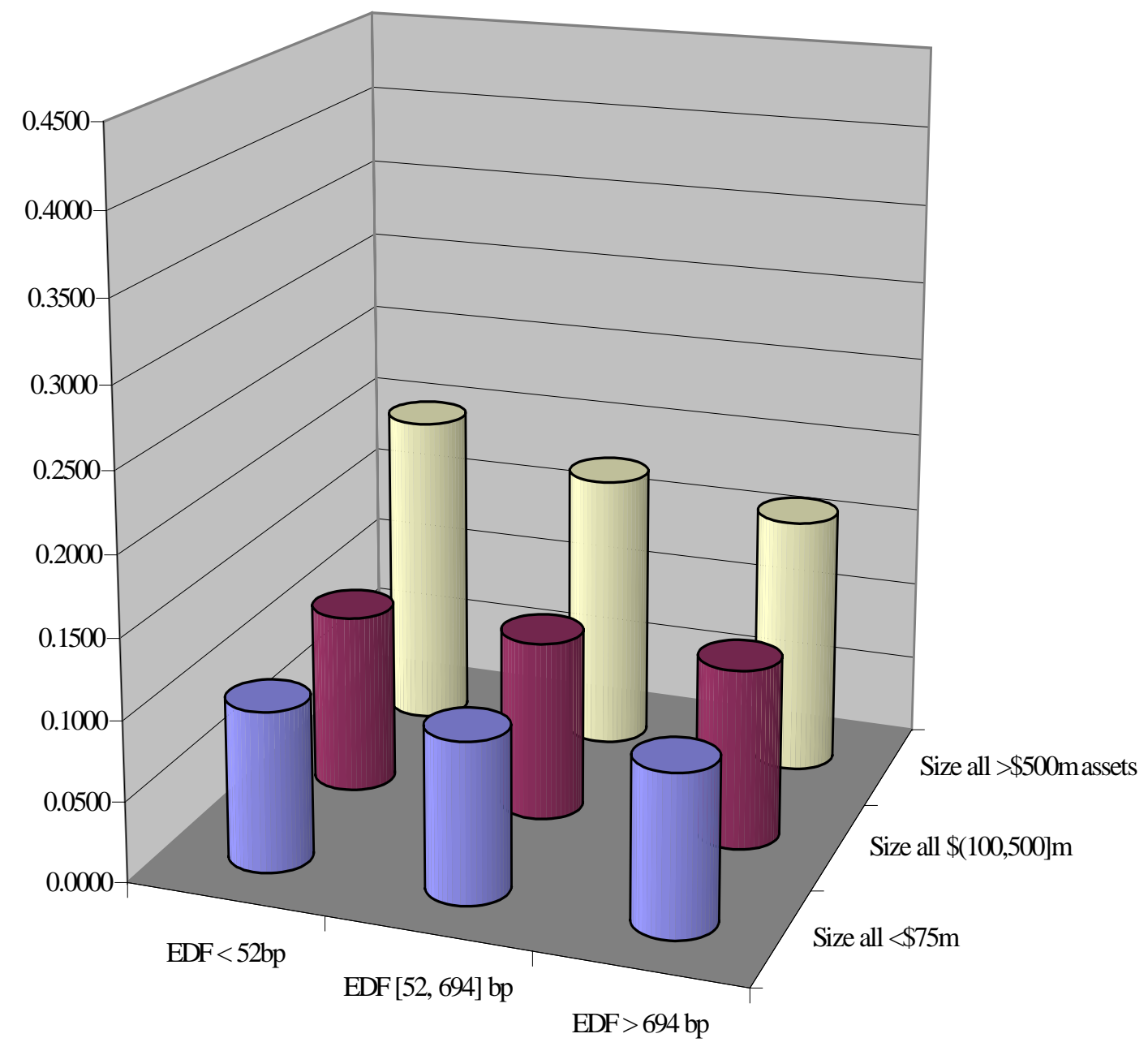


Figure 4B.

Calibrated Average Asset Correlations at the 99.9\% Percentile for U.S. Portfolios based on Firm EDF and Asset Size Categories

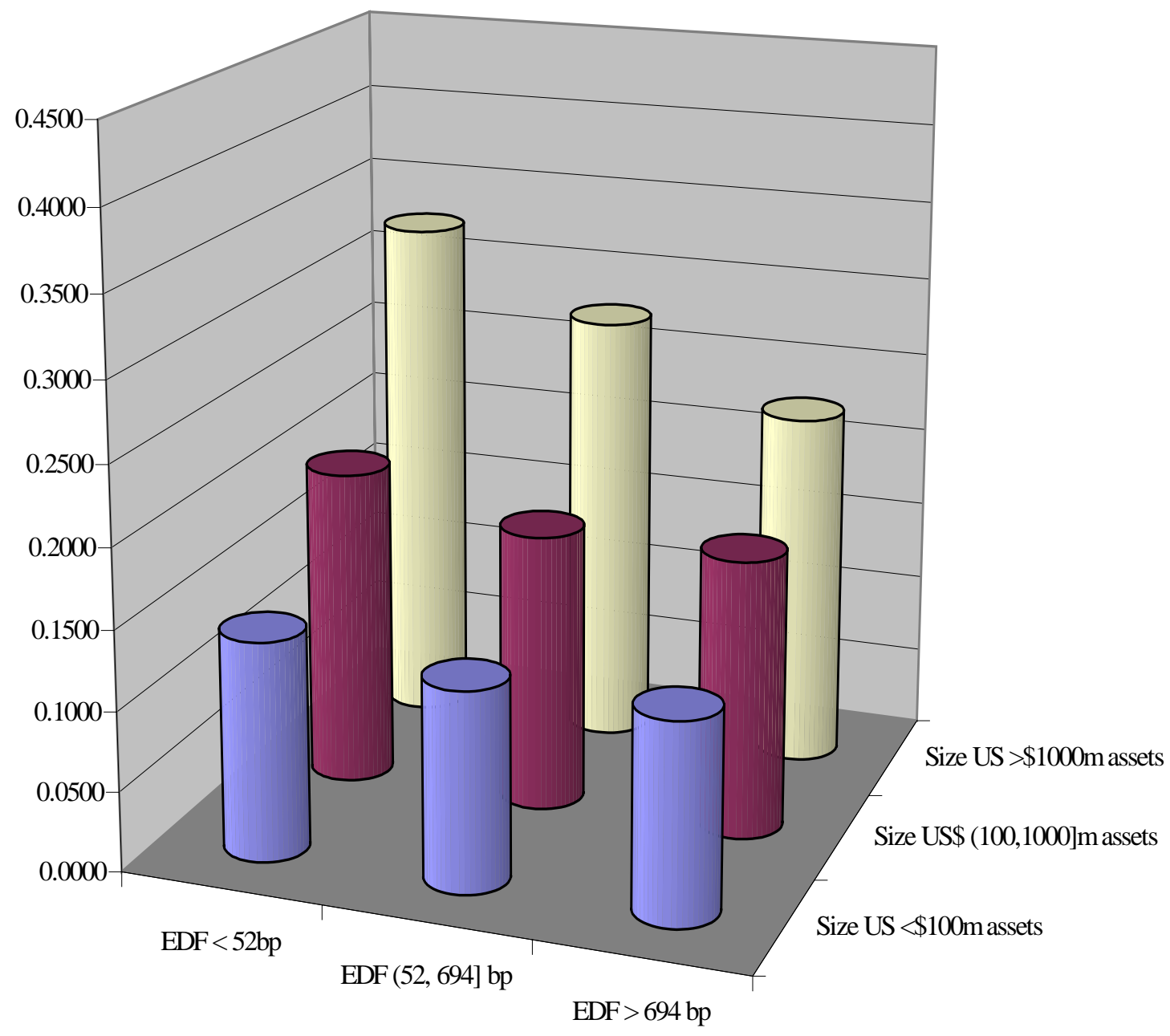




\section{Figure 4C.}

\section{Calibrated Average Asset Correlations at the 99.9\% Percentile for Japanese Portfolios based on Firm}

EDF and Asset Size Categories

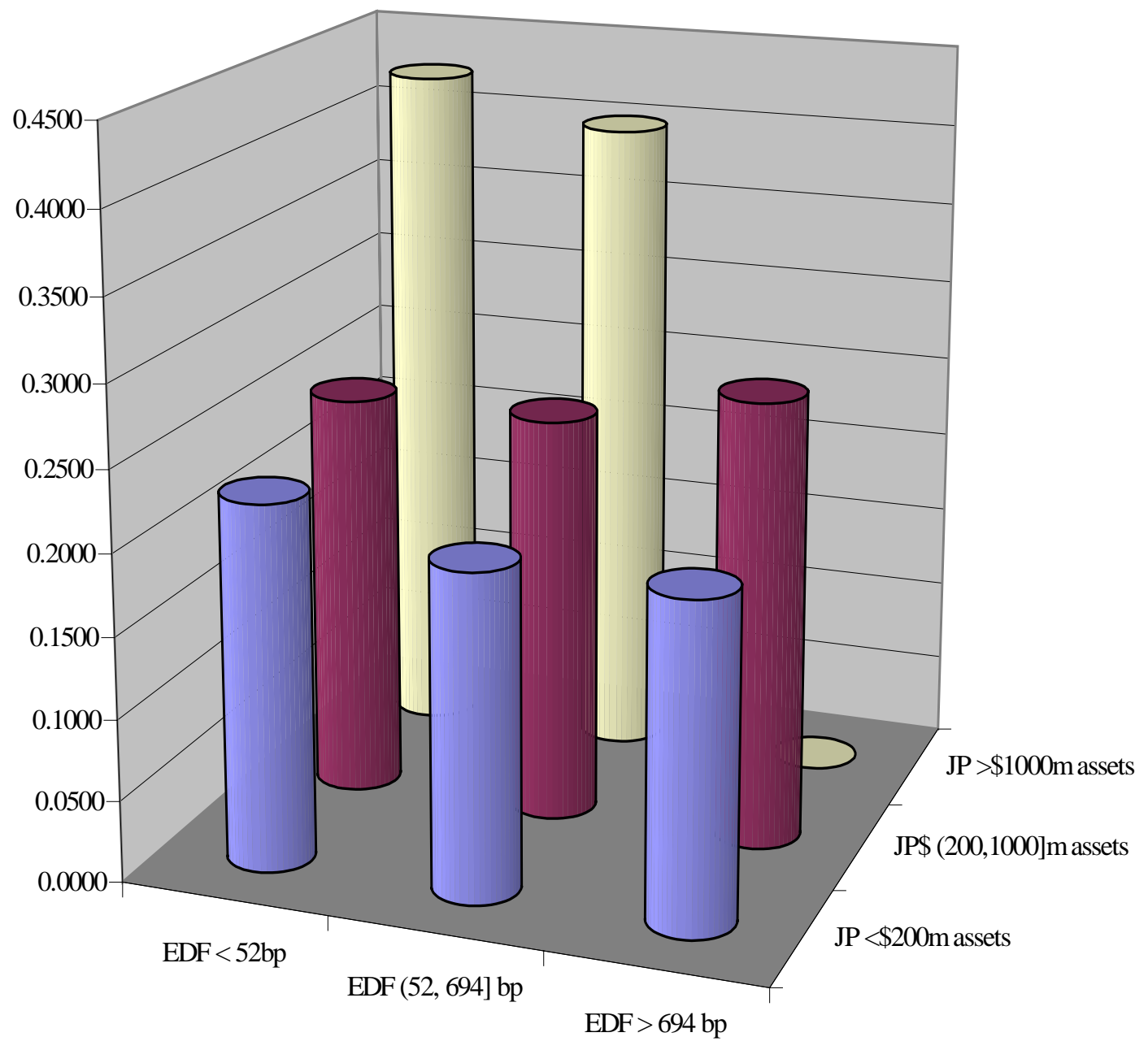

Note that the calibrated average asset correlation for the Japanese portfolio based on the highest EDF and asset size categories is not plotted here in order to preserve the comparability of the other eight calibrated values. The average asset correlation for that portfolio was calibrated to be 0.5500 . 
Figure 4D.

Calibrated Average Asset Correlations at the 99.9\% Percentile for European Portfolios based on Firm EDF and Asset Size Categories

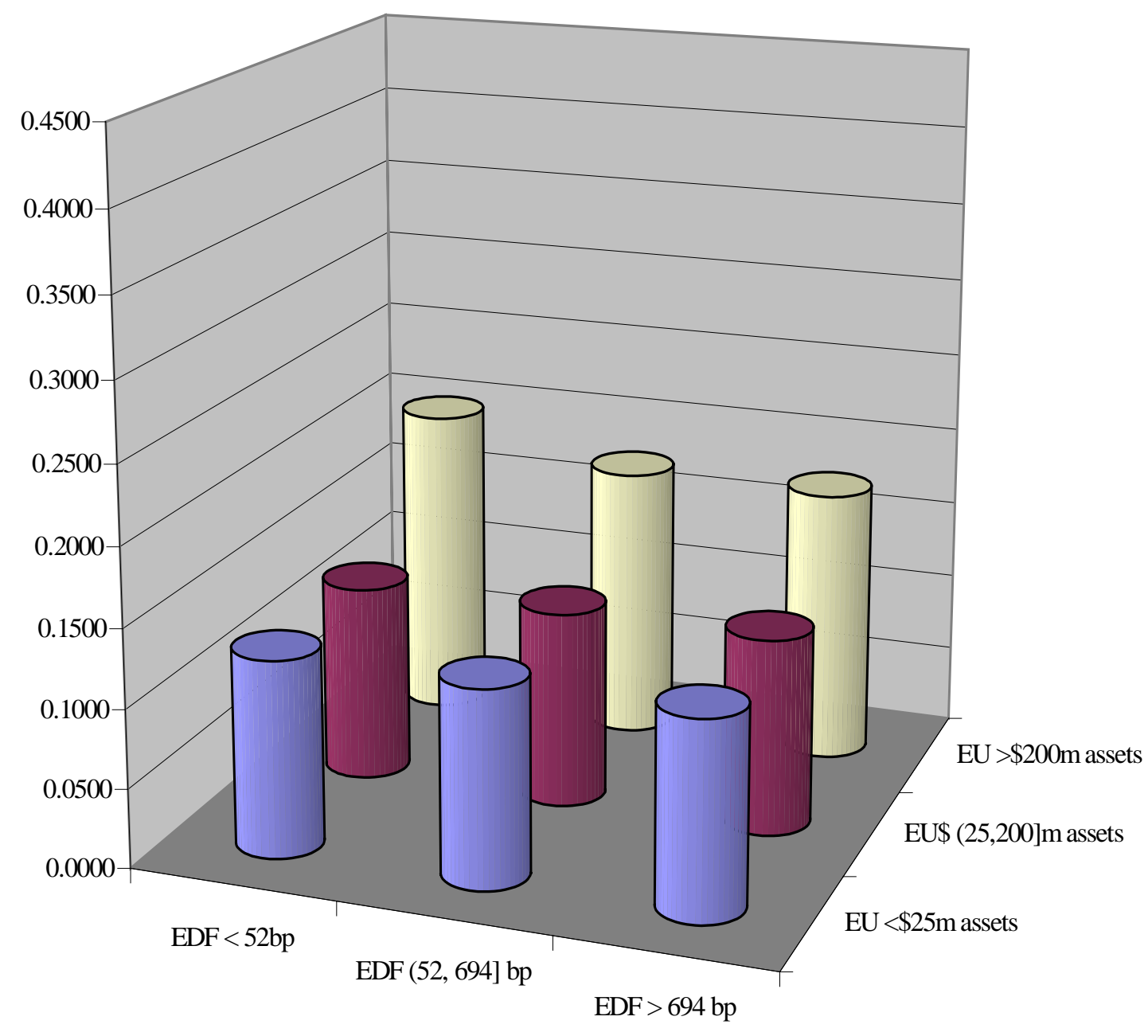


Figure 5.

\section{Asset correlation as a function of firm probability of default as per the November $2001 \mathrm{BCBS}$ proposal}

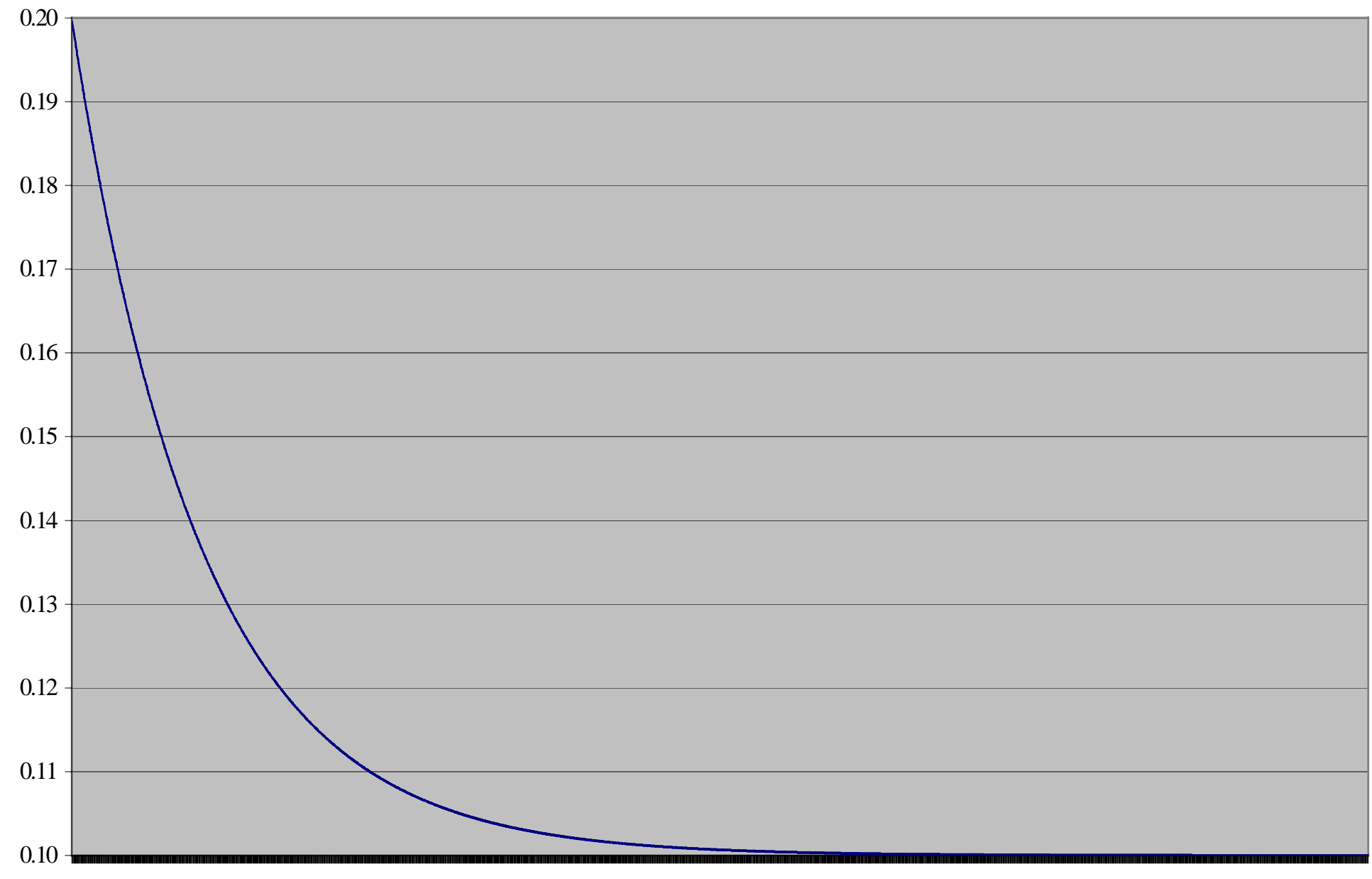

$\begin{array}{lllllllllllllllllllllllll}0.0 \% & 1.0 \% & 2.0 \% & 3.0 \% & 4.0 \% & 5.0 \% & 6.0 \% & 7.0 \% & 8.0 \% & 9.0 \% & 10.0 \% & 11.0 \% & 12.0 \% & 13.0 \% & 14.0 \% & 15.0 \% & 16.0 \% & 17.0 \% & 18.0 \% & 19.0 \%\end{array}$

Firmprobablity of default 
Figure 6.

Comparison of Calibrated and Regulatory Average Asset Correlations at the 99.9\% Percentile for the Aggregate Portfolios

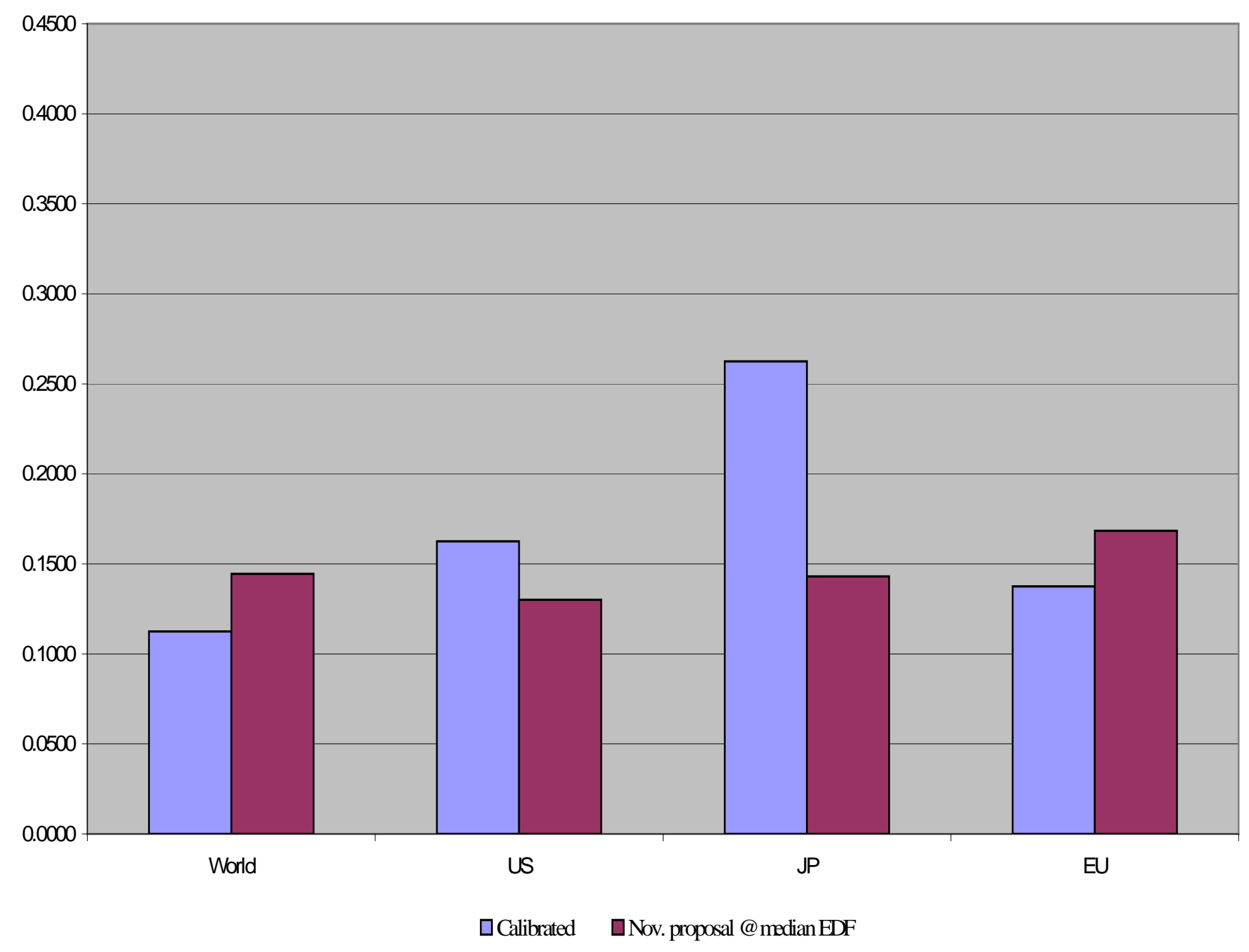


Figure 7.

\section{Difference between the Regulatory and Calibrated Average Asset Correlations at the 99.9\% Percentile for the Portfolios based on EDF Categories}

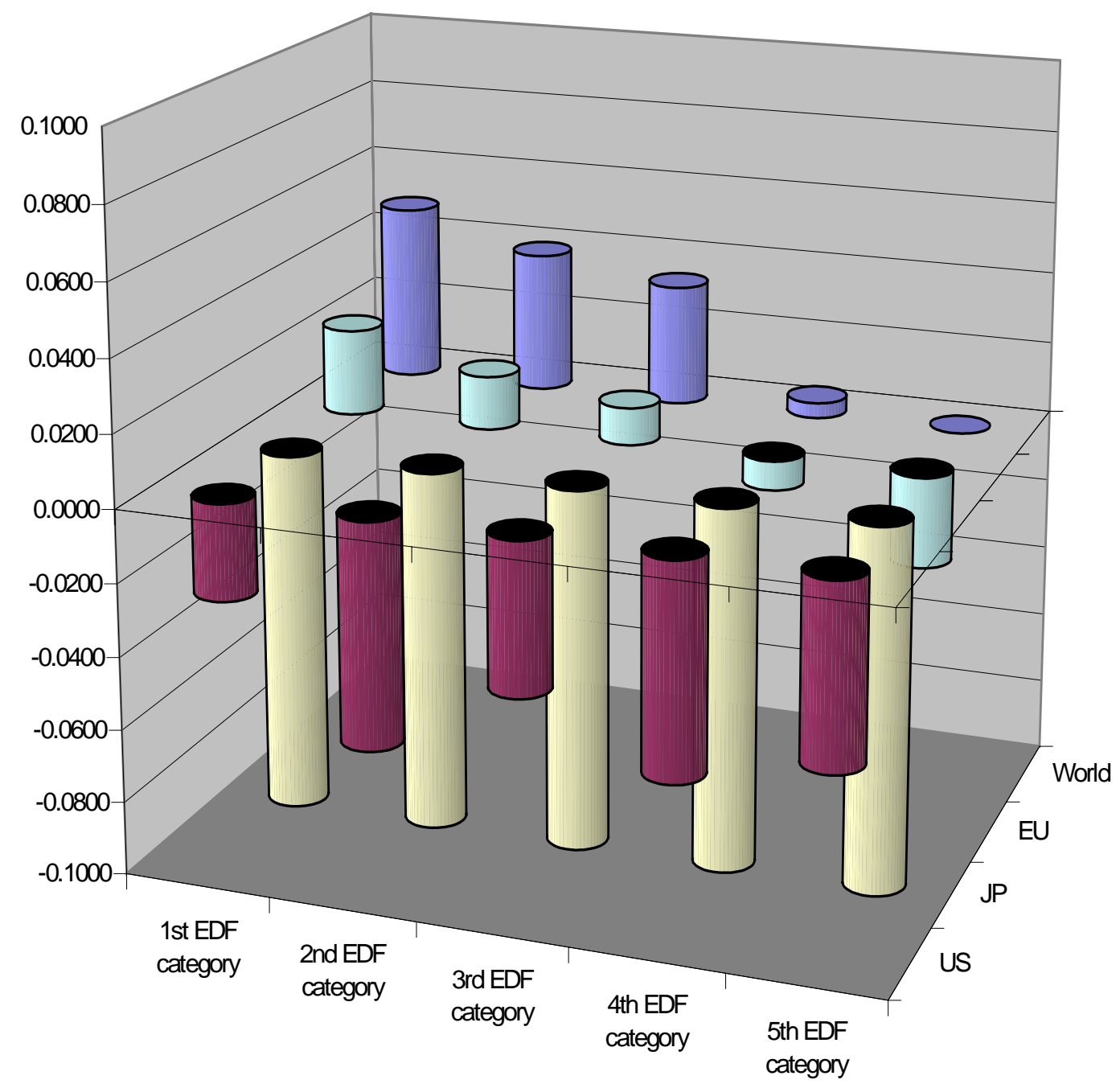

The figure plots the difference between the average asset correlation derived from the November 2001 regulatory proposal for the portfolios' median EDF values and the calibrated average asset correlations. The graph is truncated at \pm 0.1000 in order to maintain a reasonable scaling. Differences beyond these cutoff values are noted separately. For example, the actual differences for the five Japanese portfolios are $-0.1265,-0.1363,-0.1184,-0.1330$ and -0.1747 , respectively. 
Figure 8.

\section{Difference between the Regulatory and Calibrated Average Asset Correlations at the $\mathbf{9 9 . 9 \%}$ Percentile for the Portfolios based on Asset Size Categories}

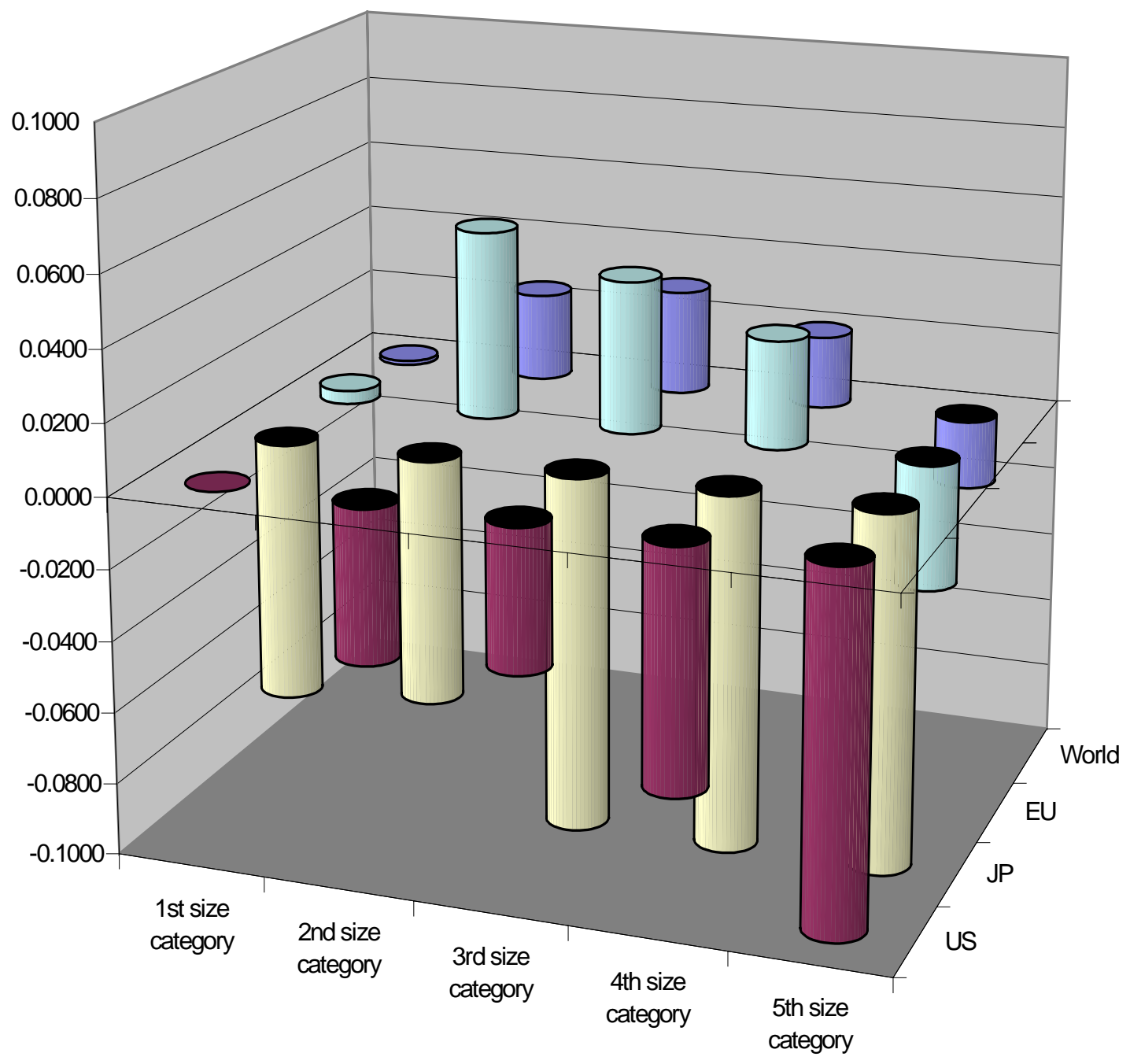

The figure plots the difference between the average asset correlation derived from the November 2001 regulatory proposal for the portfolios' median EDF values and the calibrated average asset correlations. The graph is truncated at \pm 0.1000 in order to maintain a reasonable scaling. Differences beyond these cutoff values are noted separately. For example, the actual differences for the last three Japanese portfolios are $-0.1130,-0.1583$, and -0.2767 , respectively. 
Figure 9A.

Difference between the Regulatory and Calibrated Average Asset Correlations at the $99.9 \%$ Percentile for the World Portfolios based on EDF and Asset Size Categories

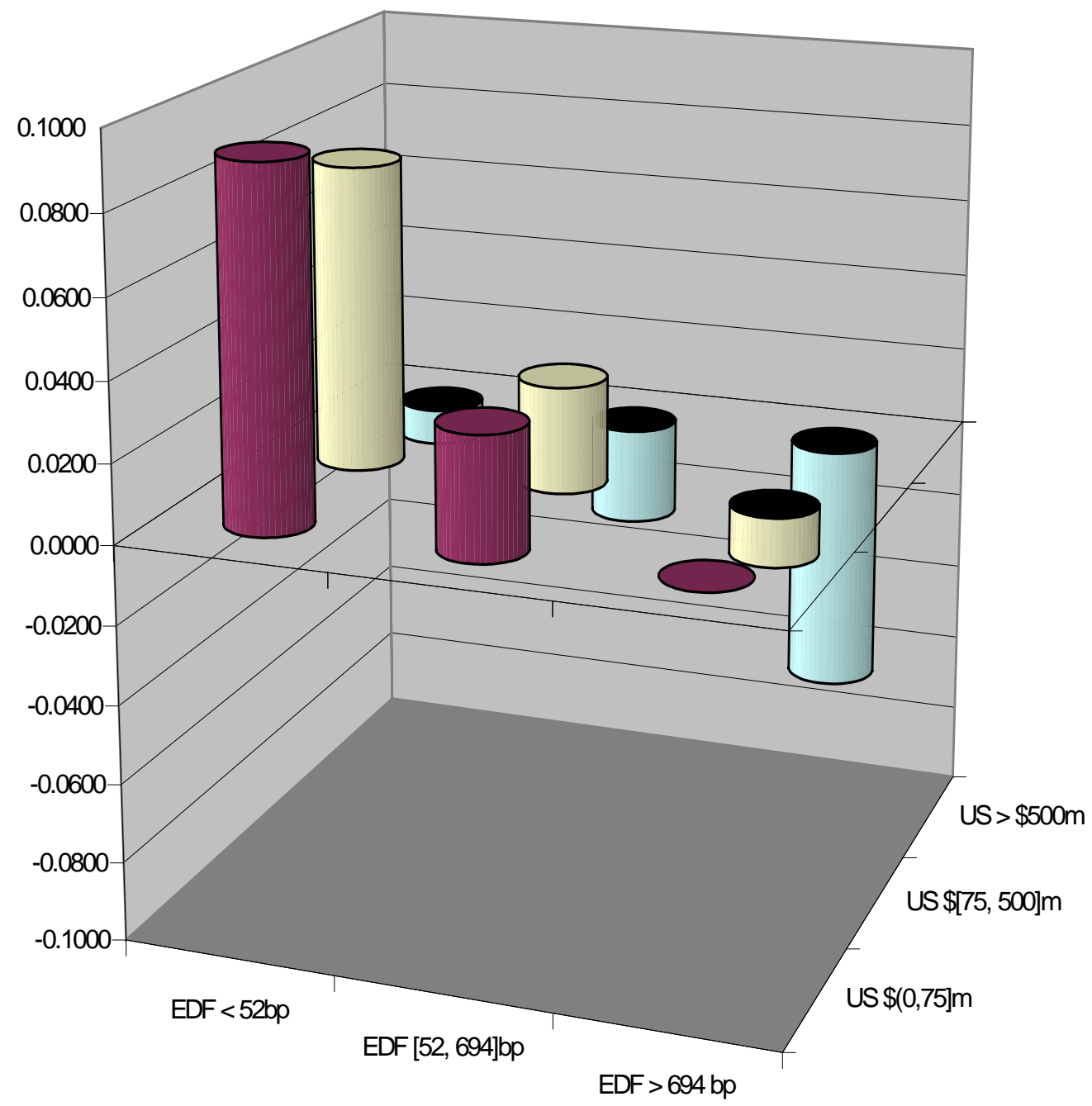

The figure plots the difference between the average asset correlation derived from the November 2001 regulatory proposal for the portfolios' median EDF values and the calibrated average asset correlations. The graph is truncated at \pm 0.1000 in order to maintain a reasonable scaling. Differences beyond these cutoff values are noted separately. 
Figure 9B.

\section{Difference between the Regulatory and Calibrated Average Asset Correlations at the $99.9 \%$ Percentile for the US Portfolios based on EDF and Asset Size Categories}

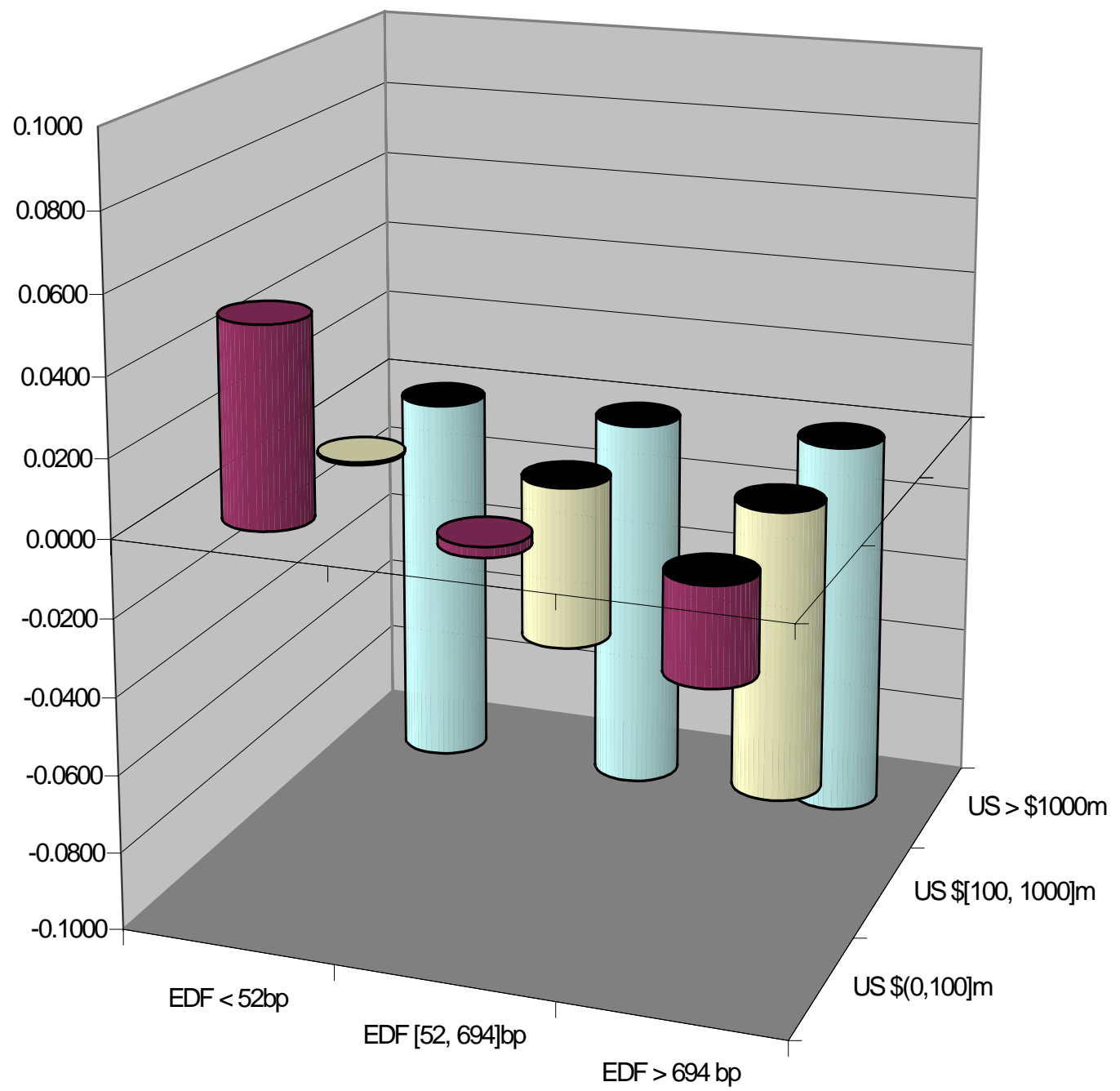

The figure plots the difference between the average asset correlation derived from the November 2001 regulatory proposal for the portfolios' median EDF values and the calibrated average asset correlations. The graph is truncated at \pm 0.1000 in order to maintain a reasonable scaling. Differences beyond these cutoff values are noted separately. For example, the actual differences for the three portfolios within the largest size category are $-0.1350,-0.1216$, and -0.1250 , respectively. 
Figure 9C.

\section{Difference between the Regulatory and Calibrated Average Asset Correlations at the 99.9\% Percentile for the Japanese Portfolios based on EDF and Asset Size Categories}

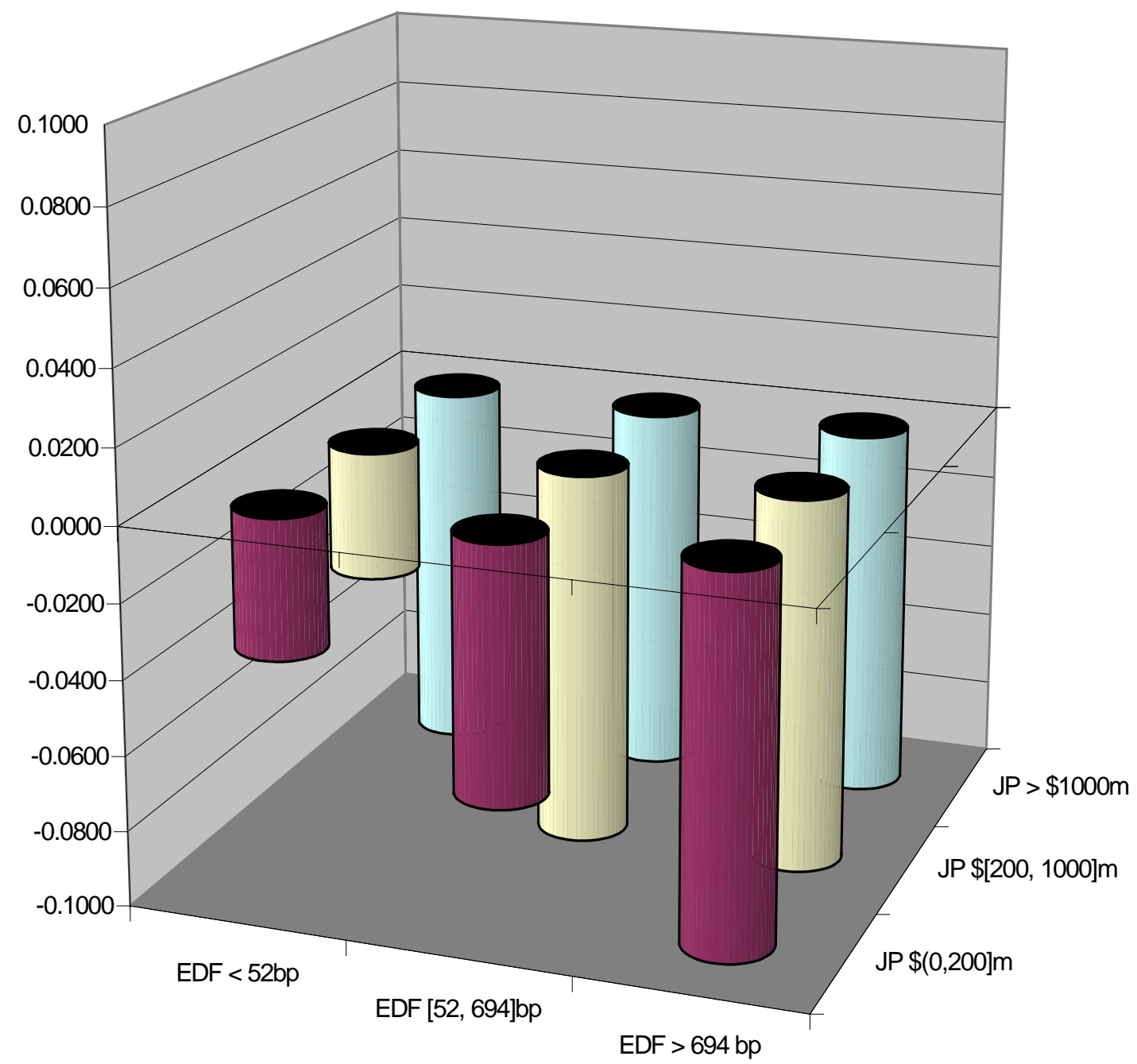

The figure plots the difference between the average asset correlation derived from the November 2001 regulatory proposal for the portfolios' median EDF values and the calibrated average asset correlations. The graph is truncated at \pm 0.1000 in order to maintain a reasonable scaling. Differences beyond these cutoff values are noted separately. For example, the actual differences for the two largest EDF portfolios within the middle size category are -0.1130 and -0.1745 , respectively. The actual differences for the three EDF portfolios within the largest size category are $-0.2347,-0.2523$, and -0.4498 , respectively 
Figure 9D.

\section{Difference between the Regulatory and Calibrated Average Asset Correlations at the $99.9 \%$ Percentile} for the European Portfolios based on EDF and Asset Size Categories

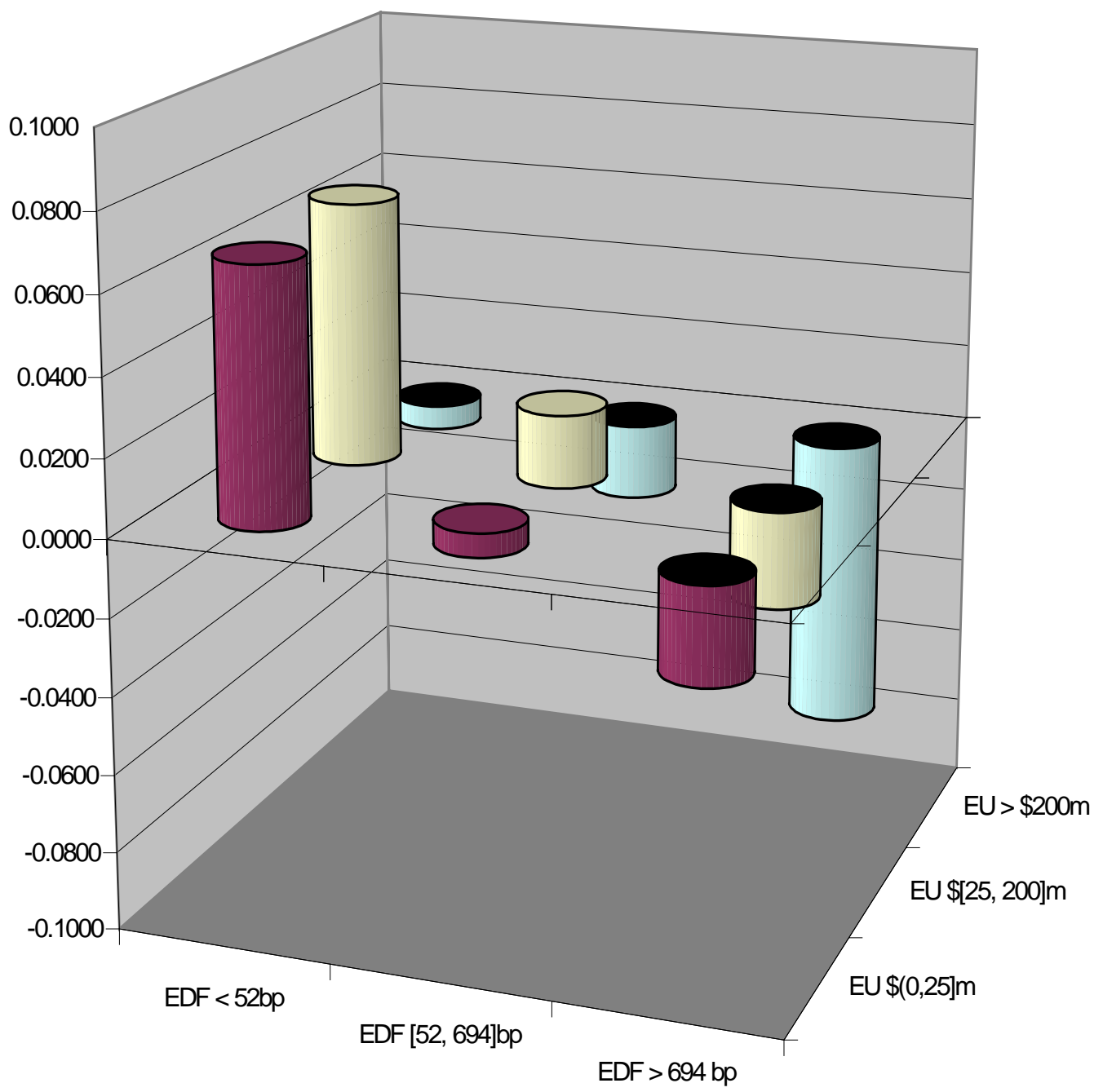

The figure plots the difference between the average asset correlation derived from the November 2001 regulatory proposal for the portfolios' median EDF values and the calibrated average asset correlations. The graph is truncated at \pm 0.1000 in order to maintain a reasonable scaling. Differences beyond these cutoff values are noted separately 